\title{
Rare Events and Risk Perception: Evidence from Fukushima Accident*
}

Renaud Coulomb

March 9, 2016

\begin{abstract}
We study changes in nuclear-risk perception following the Fukushima nuclear accident of March 2011. Using an exhaustive registry of individual housing transactions in England and Wales between 2007 and 2014, we implement a difference-in-difference strategy and compare housing prices in at-risk areas to areas further away from nuclear sites before and after Fukushima incident. We find a persistent price malus of about $3.5 \%$ in response to the Fukushima accident for properties close to nuclear plants. We show evidence that this price malus can be interpreted as a change in nuclear-risk perception. In addition, the price decrease is much larger for high-value properties within neighborhoods, and deprived zones in at-risk areas are more responsive to the accident. We discuss various theoretical channels that could explain these results.
\end{abstract}

JEL codes: D80, Q51, Q53, R21, R23, R31.

Keywords: Hedonic prices, housing markets, risk perception, nuclear power.

${ }^{*}$ Coulomb: corresponding author; The University of Melbourne, Department of Economics, Level 4, Faculty of Business and Economics Building 105, 111 Barry Street Carlton VIC 3053; renaud.coulomb@unimelb.edu.au; Zylberberg: Bristol University, Department of Economics; yanos.zylberberg@bristol.ac.uk. We thank Steve Gibbons for access to Nationwide datasets and Tatiana Paredes-Torres for excellent research assistance. We are grateful to participants at the 2016 Environmental Economics Workshop at Monash University. R. Coulomb acknowledges support from the Faculty of Business and Economics at Melbourne University (FBE research grant) and early support from the Grantham Research Institute at the London School of Economics. 


\section{Introduction}

There is a large uncertainty in the valuation of extreme events and we should observe large fluctuations in the perception of such risk after the realization of one (very) rare event like an industrial accident or a natural catastrophe. There also exist strong variations in risk perception amongst individuals, see e.g., Slovic (1987), and such heterogeneity in knowledge about these risks, risk preferences, cultural or cognitive biases should be observed in individual reactions following the realization of an extreme event.

In this paper, we analyze the changes in nuclear-risk perception due to Fukushima nuclear accident (FNA). This major industrial accident -the largest nuclear accident after Chernobyl- was triggered by the Great East Japan earthquake on March, 11 2011 and had a worldwide media coverage. A rare catastrophe of this amplitude is a salient signal on a risk whose perception is arguably blurry for a majority of individuals, even in countries already relying on nuclear power, e.g., Japan, the United States, France or the United Kingdom.

We identify the changes in nuclear-risk beliefs using an hedonic approach: we draw upon an exhaustive registry of individual housing transactions between 2007 and 2014 in England and Wales. In order to capture the extent to which agents respond to this signal on nuclear risk, we compare treated neighborhoods to control neighborhoods. We rely on the Fukushima Daiichi evacuation process (Japanese Government, 2011) in which an evacuation zone of $20 \mathrm{~km}$ around teh plant has been set, and define treated neighborhoods in England and Wales as being within a $20 \mathrm{~km}$ radius around a nuclear site. In a first step, we use a difference-in-difference strategy and compare housing prices and transaction volumes in areas within a radius of 20 kilometers around an active nuclear plant to areas between 20 and 100 kilometers before and after the Fukushima incident. In a second step, we analyze beliefs' update as captured by the price decrease across different environments both in terms of preand post-catastrophe access to information.

First, we document that housing prices strongly decrease in the wake of the Fukushima catastrophe around active nuclear power plants (NPP) in England and Wales. The price malus of about $3.5 \%$ is observed across a variety of specifications, e.g., controlling for differential trends across observable characteristics of postcodes or different definitions for treated and control groups. This price effect is persistent throughout the post-Fukushima period (March 2011-September 2014). ${ }^{1}$

\footnotetext{
${ }^{1}$ We document a very limited liquidity effect: the number of transactions only drops by $1.0 \%$ close to NPPs due to Fukushima. We provide evidence of a similar qualitative shift in the housing demand around nuclear waste sites even though smaller in magnitude.
} 
Second, there exists a large disparity in the price revision across the different price quantiles. There is a contraction of the price distribution in treated zones, with a much larger price decrease for the top quantiles than for the bottom quantiles. We also find that deprived areas close to NPPs are more responsive to FNA.

The impact of Fukushima accident on UK housing market could go through two channels: a risk-perception channel and a local-economy channel. Individuals can update their beliefs about nuclear risks in the wake of Fukushima which, coupled with an aversion to nuclear risk, would shift housing demand downward. Agents may also expect future massive layoffs and a substantial reduction of the nuclear program that may lead to further deterioration in the local economic prospects, e.g., through losses in local tax revenues and degradation of public goods and services. We perform three robustness checks to test for the presence of a local-economy channel. First, in the United Kingdom, Fukushima has not threatened the continuation of nuclear programs: the life extension of almost all nuclear reactors was announced at the end of 2012 and we do not find any price rebound around this period. Second, we do not find any differential effects across areas with different shares of employment devoted to the nuclear site. Third, we do find a non-negligible price decrease around nuclear waste sites. These waste sites are not susceptible to close down, and have little economic externality on the neighborhoods. We conclude from these tests that our findings are only explained by a strong revision of beliefs in nuclear risk.

Our paper indirectly contributes to the vast literature on the valuation of local (dis)amenities. ${ }^{2}$ There is no consensus on the overall effect of the presence of a nuclear plant on local housing and land markets. In cross-sectional analyses, Folland and Hough (1991) find a negative impact while Gamble and Downing (1982) and Clark et al. (1997) have concluded that the proximity to nuclear plants does not affect properties prices. More recent papers adopt a panel approach - tracking through time changes before and after the opening or the closure of a facility (Muehlenbachs et al., 2014) or a regression-discontinuity design (Greenstone and Gallagher, 2008). Muehlenbachs et al. (2014) study the impact of shale gas development on housing prices in Pennsylvania. They find a negative impact of the proximity to a gas well only for ground-water dependent homes. Greenstone and Gallagher (2008) find no specific effect of the Superfund cleanups on the housing market, suggesting that the negative externalities that represent hazardous waste sites are not priced in

\footnotetext{
${ }^{2}$ Different types of disamenities have been studied such as hazardous waste sites (Gayer et al., 2000; Greenstone and Gallagher, 2008; Kiel and Williams, 2007), waste incinerators (Kiel and McClain, 1995), wind farms (Gibbons, 2014), coal-fired power plants (Blomquist, 1974; Davis, 2011), major infrastructure such as airports or highways, railways stations (Anselin and LozanoGracia, 2008; Carruthers and Clark, 2010; Cohen and Coughlin, 2008; Debrezion et al., 2007; Hughes and Sirmans, 1992).
} 
housing markets. Our findings may complement these results by showing that agents revise their risk perceptions following a salient catastrophe, and that such revision is reflected in market prices. The mitigated results on the relationship between presence of a nuclear plant and local housing market may illustrate an heterogeneity in risk perception in addition to potential risk aversion. One shortcoming of most hedonic studies focusing on plant opening-closing down is that risk perception cannot be untangled from local-economic impacts. The installation of a NPP has positive economic impacts driven by an inflow of skilled workers working for the NPP and that are not reluctant to live in the NPP vicinity (Kivimäki and Kalimo, 1993), local tax revenues can be significantly increased by the contributions of a NPP tending to reduce the tax burden for other citizen or upgrade valuable amenities such as schools in the surroundings of the NPP (Bezdek and Wendling, 2006).

In stark contrast with these papers, we rely on an environment in which the market valuation of being in the proximity to existing nuclear plants only changes through a shift in risk perception. Our quasi-experiment did not threaten the existence of UK nuclear plants and did not change the actual risk through new safety regulations for instance. In contrast with the Japanese market, the United Kingdom market was not directly affected by the catastrophe. ${ }^{3}$ The United Kingdom did not reevaluate its nuclear program following Fukushima, contrary to most nuclear-power countries. For instance, Fukushima triggered changes in the German or Chinese nuclear programmes, such as modifications of safety regulations, shutdowns of plants or compensations for people living in at-risk areas. Bauer et al. (2013) give evidence of a negative economic impact of Fukushima accident on local German housing market due to the shutdown of eight NPPs and the phasing-down of the remaining NPPs. Zhu et al. (2015) find a very short-term negative effect of land prices on Chinese land primary market, potentially explained by the announcement of safety reviews of all NPPs in the country, and interference from local politicians. ${ }^{4}$

Our paper closely relates to Fink and Stratmann (2013) and Bléhaut (2014). Using a dataset on housing prices in the US, ${ }^{5}$ Fink and Stratmann (2013) find no

\footnotetext{
${ }^{3}$ Nelson (1981) and Managi and Tanaka (2014) study the impact of a nuclear accident or radioactivity exposure on housing prices nearby an accident location. Using panel survey data, Hanaoka et al. (2014) study how risk preference of individuals that have directly experienced the Great Eastern Earthquake has been modified by the disaster.

${ }^{4}$ Land supply is provided by local governments and not by households, and local politicians may also be involved in the safety procedures around nuclear plants. See Viscusi and Hamilton (1999) who study how political demands shape cleaning decisions of hazardous waste sites made for the US Superfund Program.

${ }^{5}$ The authors use data on median value for all-single-family houses within a postcode estimated monthly by a private company Zillow and according to a method proprietary to this company. Zillow Price Index is available for 10,419 US postcodes in the US, and the very short period of analysis goes from February 2011 to September 2011.
} 
particular effect of Fukushima accident on properties prices. Bléhaut (2014) studies the impact of the AZF industrial accident in France in 2001 on local housing markets and finds no price effect in at-risk areas.

The remainder of this paper is structured as follows. In Section 2, we describe our data and our main empirical strategy. Sections 3 and 4 present our main findings, exploring first the average effect of Fukushima on the functioning of housing markets and second the distributional effects. Section 5 briefly concludes.

\section{Data and empirical strategy}

This section briefly presents the context, describes our data construction and our main empirical strategy, and finally discusses some descriptive statistics.

\subsection{Fukushima nuclear accident and nuclear risk in England}

The Fukushima nuclear accident had a marked impact on the perception of nuclear risk, generating unprecedented reactions in Japan but also other countries with a similar nuclear fleet. In this paper, we study one potential impact through the functioning of housing markets in a country that resembles Japan in its nuclear strategy, i.e., the United Kingdom.

In the following lines, we briefly describe the Fukushima nuclear accident and its impact in England and Wales.

Fukushima nuclear accident A major tsunami triggered by the Great East Japan earthquake hit the Fukushima Daiichi nuclear plant (FNP) on March 11, 2011 leading to a failure of coolant systems and large radioactive leakages due to this equipment damage. This accident was given the highest level (Level 7) in the classification of the International Nuclear Event Scale, a level shared only with the Chernobyl accident of $1986 .{ }^{6}$

In the weeks following the tsunami, information was given about the nuclear cores meltdown of three reactor units in the plant. The Japanese government response consisted in setting a prohibited access area out to $3 \mathrm{~km}$ from the plant, an on-alert area 3-20 km and an evacuation prepared area 20-30 km. On 21 April 2011, a 20-km zone around the plant was defined as a "no-go" zone by the Japanese government. Some areas outside this zone were later evacuated based on radiation measures.

Information releases about the accident were not circumscribed to the immediate aftermath. In July 2012, the Fukushima Nuclear Accident Independent Investigation

\footnotetext{
${ }^{6}$ However, the Fukushima disaster remained of smaller magnitude than the Chernobyl disaster in terms of radiation releases.
} 
Commission revealed that the regulatory institutions had overestimated the capacity of power stations to resist such earthquake and tsunami. The Tokyo Electric Power Company (TEPCO) recognized later having failed in taking the adequate preventive measures.

The failure of safety measures monitored by supposedly-independent regulatory agencies questioned the whole system of nuclear supervision in Japan, but also in other countries. Following Fukushima, a large number of TEPCO executives were identified as former independent supervisors and the same conflicts of interest were detected in European countries. Overall, Fukushima raised a vast number of questions regarding the actual safety around nuclear power stations across the World, particularly so because the Japanese system was considered as one of the safest with conservative technologies. ${ }^{7}$

Nuclear context and response to Fukushima accident in England In order to properly identify changes in nuclear risk perception from changes in housing prices nearby Nuclear Power Plants (NPPs), it is important to understand how the nuclear context in England and Wales compares to Japan, and how the general recourse to nuclear technology was discussed in the aftermath of the catastrophe.

Nuclear fleet in England and Wales includes 12 operational nuclear reactors. Adding the two operational plants located in Scotland, nuclear account for about $20 \%$ of domestic electricity generation in the United Kingdom in 2010 (IEA, 2014). To contrast, in Japan, almost 50 reactors generate $30 \%$ of the country's electricity. The size of the nuclear sector in England is markedly lower than in Japan but the two countries shared similar objectives before the catastrophe, i.e., a reinforcement of the nuclear fleet and a slow transition to the next-generation power plants.

This line of conduct has not been modified by the Fukushima disaster in the United Kingdom: there was no premature shutdown of power plants. Conversely, the United Kingdom kept a pro-nuclear position after the accident and Secretary of State (SoS) for Energy and Climate Change Chris Huhne criticized European leaders for their haste in stopping their nuclear development projects. In the immediate aftermath of Fukushima, Chris Huhne asked Dr Mike W. Weightman HM Chief Inspector of Nuclear Installations to write a report (Weightman, 2011) on the implications of Fukushima for UK nuclear industry. In a letter to Dr Mike W. Weightman, dated June 2011, Chris Huhne responded to the Interim report and wrote "Having considered your findings, I see no reason why the UK should not

\footnotetext{
${ }^{7}$ The Boiling Water Reactors (BWR) are supposed to be safer than the Pressurized Water Reactors (PWR) which are used in the United States, France, or recently the United Kingdom.
} 
proceed with our current policy: that nuclear should be part of the future energy mix [...]." In December 2012, this position was made official with the renewal of all nuclear power stations with expected closure between 2019 and 2035. This position clearly contrasted with the German one: Chancellor Angela Merkel decided to shutdown eight of the seventeen German NPPs directly after Fukushima and to phase-down by 2022 all the remaining ones.

Overall, in the United Kingdom, the expectations concerning possible phase out of operational plants in the wake of Fukushima were nil or very short-lived. No economic effect that could be triggered by NPPs phase out - like a labor workforce outflow or a loss of local tax base - were expected to occur in areas nearby NPPs. This feature makes the UK context very suitable for isolating changes in nuclear-risk perception only.

Poortinga et al. (2013) have showed that British opinion on nuclear risk was relatively stable despite Fukushima accident. As indicated by opinion polls around the accident, the British support for replacing aging nuclear plants first decreased right after Fukushima as in most countries in the world. Support felt by 11 points at $36 \%$ in June 2011 compared to November 2010. However, this drop was short-lived, and nuclear support reached 50\% in December 2011.

\subsection{Treatment}

The sources of exposure to nuclear residuals in England and Wales are multiple and may differ both in magnitude and in nature. In our main specification, we will not distinguish between Nuclear Power Plants in spite of some technological disparities, and we will treat similarly all neighborhoods at a given distance of any active nuclear plant. However, we will distinguish nuclear waste sites from Nuclear Power Plants and estimate their effect separately.

In the following lines, we describe the catalogue of nuclear plants/waste sites in England and Wales, and we define our treatment measures.

Nuclear plants In March 2011, there were 10 active nuclear plants in the United Kingdom that could threaten some English neighborhoods (see Table 1 and Figure 1). Data on nuclear plants are from the Department of Energy \& Climate Change (DECC). ${ }^{8}$

These nuclear plants present some differences in their technologies. A dozen of nuclear power reactors were constructed during the 1960s and early 1970s with the

8“Table of past and present UK nuclear reactors" available at
https://www.gov.uk/government/publications.


UK-specific Magnox technology. These reactors were designed such as to operate either as a power plant or as a producer of plutonium for weapons. While being quite safe, this Magnox technology has been unsuccessful. ${ }^{9}$ In 2011, only Oldbury and Wylfa were still active and these two power stations had a low radiation dose despite their obsolete technology.

A second generation of seven reactors (Advanced Gas-cooled Reactors, AGR) were constructed between 1975 and 1988 to replace the Magnox power plants. As for the Magnox technology, this technology could not be competitive enough to be exported outside the United Kingdom. Being considered safe, these power plants were given life extensions even after the Fukushima incident. For instance, EDF announced the expected life extension of all AGR reactors in February 2012 (with expected closure ranging between 2019 and 2028).

Finally, Sizewell B, connected to the grid in 1995 and expected to close down in 2035, operates under the PWR technology (Pressurized Water Reactor).

It may be useful to compare these power plants to the Fukushima Daiichi Nuclear Power Plant. All active power plants in the United Kingdom are almost three times smaller than the Fukushima Daiichi Nuclear Power Plant (with 6 Boiling Water Reactors - BWR) but their technologies and regulatory systems may be less developed than in Japan.

It is difficult to determine if UK nuclear power plants are more dangerous than their Japanese counterparts. Let us remark that Dr Mike W. Weightman HM Chief Inspector of Nuclear Installations declared that after a failure of the cooling system - the industrial cause of FNA - in Magnox reactors and AGRs, "the temperature increases would be slow allowing ample time for operator intervention" because of the "low power density and high thermal inertia" of these reactors (Weightman, 2011).

For simplicity, we will assume that the level of risk implied by each NPP in England or Wales is comparable in nature to Fukushima, and that economic agents could learn about the risk from the radiation zones provoked by the Fukushima accident and the evacuation process.

In practice, for the 20 active and inactive nuclear plants in the United Kingdom, we collect some information on their capacity, the number of operating reactors, their connection to the grid and expected closure, their technology, their exact location, the number of workers employed in the NPP and a list of accidents (e.g., cracks). Interestingly, accidents do not only concern active plants but also the closed ones

\footnotetext{
${ }^{9}$ The Magnesium non-oxidizing technology is associated with low thermal efficiency, and thus high producing costs.
} 
that act (and are registered) as nuclear waste sites.

Nuclear waste sites Before 1975 and the second generation of nuclear reactors, the nuclear waste produced by military and nuclear electricity programs was stocked on the same site as nuclear power plants. Data are from the Department of Energy \& Climate Change (DECC) and the Nuclear Decommissioning Authority (NDA).

In the late 1970s, three granite sites close to the Scottish borders were examined for High Level Wastes (HLW) but they all encountered a large public opposition and were abandoned. ${ }^{10}$ Only the Sellafield site, in the North-West of England, is used to store High Level Wastes. ${ }^{11}$

Despite similar public opposition, the storage of Intermediate Level Wastes (ILW) outside of nuclear power stations became more frequent. ${ }^{12}$ Nowadays, a dozen of those sites store more than $1,000 \mathrm{~m}^{3}$ of wastes produced from uranium enrichment, nuclear fuel manufacture, nuclear power production, spent fuel reprocessing, research and development, medical and industrial sources and defence activities.

In Table 9, we report the volume stored in each nuclear waste site for each waste category, its location and the site owners. In addition, we collected all radioactive wastes with its classification, volume, radioactivity concentration, material composition, treatment and packaging.

Treatment Note that our baseline analysis collapses transactions at the Lower Super Output Area (LSOA) level which comprise between 400 and 1,200 households. We choose this unit such as (i) to match Census data, and (ii) to restrict the number of observations while keeping disaggregated geographical units. Between 2007 and September 2014, we construct the number of transactions, their average price and the total volume for each LSOA for each month, which leaves us with about 1,500,000 observations.

In order to capture the extent to which a neighborhood may be affected by a nuclear incident, we rely on the Fukushima Daiichi evacuation process and define a $20 \mathrm{~km}$ evacuation zone around each nuclear site. This piece of information was disseminated worldwide by media. We define $T_{n p}=1$ for all LSOAs whose centroid

\footnotetext{
${ }^{10}$ High Level Wastes are mostly spent nuclear fuel and highly radioactive reprocessing liquors. One challenge to store them is that their temperature could rise significantly because of their radioactivity. They are currently stored in steel containers to cool down for 50 years.

${ }^{11}$ The packaged volume of nuclear waste of any type in Sellafield is higher than the combined volume for all the other sites in the United Kingdom.

${ }^{12}$ Intermediate Level Wastes are used fuel rod casings, used ion exchange resins and parts of decommissioned reactors that are very radioactive but do not require any cooling process. Low Level Wastes (LLW) are low in radioactivity, and their storage does not require very advanced facilities.
} 
is within the potential evacuation zone of any active nuclear power plant. In our preferred specification, we define $T_{n p}=0$ for all LSOAs whose centroid is in a range of 20-100 km around any active nuclear power plant but not in any potential evacuation zones. Figure 2 illustrates our treatment construction, in particular when two nuclear plants are sufficiently close for the evacuation zone of one nuclear plant to overlap with the safe neighborhood of another plant.

We apply the same methodology for nuclear waste sites (that are not nuclear power stations), and define $T_{w s}=1$ for all LSOAs whose centroid is within the potential evacuation zone of a nuclear waste site with intermediate- or high-level waste, and $T_{w s}=0$ for LSOAs in a band of $20-100 \mathrm{~km}$.

In some robustness checks, we will consider different definitions for our treatment and the control group. In particular, we will modify the distance interval defining treated and control areas, then allow for a continuous treatment.

\subsection{Housing data}

We use two sources of data on the housing market, an exhaustive register with limited controls, and a subsample of transactions with a very wide range of characteristics.

Our main empirical analysis draws on the Land Registry transaction data between January 2007 and September 2014. Under the Land Registration Act 2002 and the Land Registration Rules 2003, Land Registry registers all transactions (sales) and changes in ownership rights (mortgage, lease or right of way) in England and Wales. The transaction data is exhaustive but few characteristics are available, i.e., price, postcode, the type of property (e.g., flat, terrace house, separate house) and whether the property was built during the past 10 years.

We also rely on another data source which is based on new mortgages issued by Nationwide -the second largest company providing mortgages in the UK- between January 2007 and December 2013. We provide a description of this dataset in the appendix.

\subsection{Empirical strategy}

To estimate the impact of Fukushima on the English housing market, we collapse the data at the LSOA/month level and we use a difference-in-difference approach. We identify the market response in treated output areas versus controls between the pre-treatment period (2008-March 2011) and the post-treatment one (March 2011-September 2014).

In the benchmark specification, we control for monthly fixed effects and allow output areas in a range of 100 kilometers around each nuclear plant to have differ- 
ential trends. In a robustness check, we also allow output areas with (i) different ex-ante ecological concerns (green votes), (ii) different deprivation indices, and (iii) different workforce composition to have different trends. Finally, we also include output area fixed effects in our preferred specification to clean for time-invariant unobserved heterogeneity, and captures potential selection effects: some LSOAs may appear more often than others because transactions are more frequent and such selection could be correlated with our treatment. In the end, we identify a Fukushima effect on variations over time for output areas inside a $20 \mathrm{~km}$ circle around a plant compared to postcodes located between 20 and $100 \mathrm{~km}$ of the same plant but at least $20 \mathrm{~km}$ away from other plants.

We estimate the following baseline equation:

$$
p_{o z t}=\beta_{0}+\beta_{1} T_{o z} \times \mathbb{1}_{t>\tau}+\beta_{2} T_{o}+\beta_{3} \mathbf{X}_{o} \times t+\gamma \mathbf{X}_{o}+\delta_{z t}+\varepsilon_{o z t},
$$

where $o$ indexes an output area, $z$ stands for the neighborhood (less than 100 kilometers) of one nuclear plant and $t$ is a month/year. For our main specification on Land Registry, we will collapse the data at the LSOA/month/year level.

$p_{o z t}$, our dependent variable, will be the average price, the volume of transactions, or the number of transactions in the LSOA during a specific month depending on the specification. Our treatment $T_{o z}$ is a dummy equal to 1 if the output area is in a range of 20 kilometers around the nuclear plant $z$ (or a waste site depending on the specification) and 0 if it is between 20 and 100 kilometers, as described earlier. The vector $X$ includes transaction characteristics (new, tenure, type: flat, maisonette, terrace etc.) in our benchmark specification. In robustness checks, we add access to schools in the output area, the deprivation indices as supplied by the Social Disadvantage Research Centre and some additional controls extracted from the census (e.g., housing stock, percentage of high-educated individuals, students, retired). $\quad \delta_{z t}$ is a set of nuclear plant-specific time fixed effects that account for changes in the housing market over time in the large neighborhood of each nuclear plant. Finally, the error term will be clustered at the neighborhood level, given that there exists a large spatial correlation in our treatment.

Note that we conduct a difference-in-difference analysis comparing output areas with different proximities to a nuclear plant, before and after Fukushima. However, we can also add output area fixed effects. In such panel specification, we fully control for observed and unobserved time-invariant factors.

The close neighborhood of a nuclear plant may follow a different trend than its outward ring. For instance, the center around a nuclear plant may be a more deprived zone and these differences that reflect a different topography or a different 
history are imperfectly captured by our controls $X_{o}$. In order to test for these preexisting differential trends between treated and control areas, we run our baseline specification over the pre-accident period (between 2008 and March 2011), and we modify our treatment as if Fukushima accident had occurred in March 2010.

\subsection{Descriptive statistics}

Table 2 provides summary statistics for the average LSOA, the average LSOAs for which $T_{n p}=1, T_{w s}=1, T_{w s}=0$ and $T_{n p}=0$. On average, in 2010, there were 2.3 transactions per LSOA in a month with an average price around 230,000 pounds. There are few important differences that are worth mentioning between LSOAs in a range of 20 kilometers around a nuclear plant or a nuclear waste site and the other LSOAs. While the number of transactions per month is constant across the different subsamples, the average price is markedly lower in the close neighborhood of nuclear power stations and this malus does not seem to be related with either income or employment deprivation measures.

The nuclear-plant malus can also be seen in Figure 5. As apparent, there is a price gradient as one gets closer to a nuclear plant, especially between 0 and 20 kilometers. ${ }^{13}$ The next section will analyze the evolution of this gradient following the Fukushima catastrophe.

\section{Results}

This section is organized as follows. First, we analyze how proximity to nuclear plants or waste sites coupled with the Fukushima incident affects prices and the number of transactions in our benchmark specification, and we explore some differences across nuclear plants. Second, we provide a series of robustness checks to support our benchmark estimates. In particular, we discard the existence of pretreatment differential trends between treated and controls zones, and we show the robustness of our estimates to other definitions of treatment or to the addition of a wide range of controls.

\subsection{Housing market indicators in the wake of Fukushima}

For all specifications but the placebo checks, we restrict our sample to the period January 2007 - September 2014. We estimate three variations of specification (2). In a first step (column 1), we estimate our difference-in-difference without LSOA fixed effects, and without controls for the type of transactions. In a second step, we

\footnotetext{
${ }^{13}$ In contrast, the price gradient is less pronounced around nuclear waste sites.
} 
consider the panel specification with LSOA fixed effects (column 2), and we finally add transaction controls in column 3.

In Panel $\mathrm{A}$ of Table 3, we estimate the effect of being close to an active nuclear plant on housing market indicators in the aftermath of Fukushima. We estimate equation (2) with our treatment $T_{n p}$ for different measures of housing transactions starting with the average price (in logarithm, see line 1). We then look at the number of transactions (in logarithm, see line 2), and we derive the total effect, i.e., the sum of the price and quantity effects, in line 3 with the total volume of transactions (in logarithm). We find a price decrease of about $3.5 \%$ for transactions occurring in the neighborhood of active nuclear plants after Fukushima, and this coefficient is robust to the addition of transaction controls or LSOA fixed effects. We also find that the number of transactions decreases by about $1 \%$, and this quantity drop coupled with the price decrease implies a drop in the volume of transactions of about $4.5 \%$. Remark that the coefficients are robust across specifications: controlling for constant unobserved heterogeneity or transaction controls does not modify our conclusions.

In Panel B of Table 3, we repeat the same exercise for the effect of being close to a nuclear waste site with high-level waste or intermediary-level waste. While statistically significant, the shift in housing demand is markedly lower. The price decrease of about $2 \%$ for transactions, combined with a quantity drop of $1 \%$, generates an overall $3 \%$ drop in transaction volumes.

We have provided evidence of a shift in the housing demand around nuclear plants, and we have found a similar qualitative shift for nuclear waste sites even though smaller in magnitude. We now examine whether:

1. this shift is short-lived or persistent,

2. this shift can be related to some features of these nuclear sites.

In order to study the persistence of the effect, we separate the treated period between March 2011 and September 2014 into 2 periods, March 2011-November 2012, December 2012-December 2013, and we run specification (2) with the two different treated periods. We report the results in Table 7 . There is no sign that the effect was short-lived, and the price malus is even a bit larger after December 2012, reflecting potentially an announcement effect: the contract renewals of nuclear plants were announced in 2012. In parallel, there is no clear indication of liquidity shortages just after the catastrophe: the decrease in the number of transactions is small and not very statistically significant (see Panel B of Table 7).

In order to study how the effect differs across nuclear sites, we estimate the 
following baseline specification:

$$
p_{o z t}=\beta_{0}+\beta_{i n t} T_{o z} \times \mathbb{1}_{t>\tau} \times N P_{o z}+\ldots+\beta_{2} T_{o z}+\beta_{3} \mathbf{X}_{o} \times t+\gamma \mathbf{X}_{o}+\delta_{z t}+\varepsilon_{o z t},
$$

where $o$ indexes an output area, $z$ stands for the neighborhood (less than 100 kilometers) of one nuclear plant and $t$ is a month/year. For the sake of exposure, we omit all the $2 \times 2$ interactions between $T_{o z}, \mathbb{1}_{t>\tau}$ and the nuclear site features $N P_{o z}$. We report the estimates for $\beta_{\text {int }}$ in Table 4 . As nuclear site characteristics, we use the year of connection to the grid (between 1971 and 1995 across plants, column 1), the year of expected closure (between 2014 and 2035, column 2), the number of reported accidents (between 0 and 14) and finally the packaged volume of high-level and intermediate-level nuclear wastes (between 10 and 300 thousand $\mathrm{m}^{3}$, column 4). We find that the response in the neighborhoods of older nuclear plants is higher: the price malus is approximately 2 percentage points higher for the oldest plant relatively to the newest (see column 1). Since the correlation between the age of a nuclear plant and its closure is extremely correlated, it also implies that the malus is larger for plants whose lifetime is smaller. ${ }^{14}$ Age is not the only feature which matters. Agents also react more in the neighborhood of the largest waste sites: the malus ranges from 0 for sites with almost no nuclear waste to $8 \%(300 \times .000279$, see column 4) for the largest waste site. This result is not really surprising: the smallest waste sites are not extremely visible and their presence is often ignored by the general public. In contrast, the number of accidents does not seem to matter (see column 3). We also construct the ratio of the NPP employees to the number of labor market participants in a radius of $20 \mathrm{~km}$ and interact this ratio with our treatment (see column 5 of Table 4). While the interaction is significantly different from 0 , it is positive indicating that neighborhoods with the larger NPP employment ratio experience smaller price decrease. This effect is nonetheless quite small in magnitude: a standard deviation in the NPP employment ratio is associated with less than a percentage point in prices.

One corollary of the previous analyses is that the shift in housing demand is unlikely to be explained by an employment channel, i.e., the uncertainty on the life extension of some power plants and the related expected downturn in local activity. Indeed, as shown before, we do not find a larger demand shift when the closure threat is larger. First, the weight of the nuclear power station in the local employment strongly differs across nuclear plants but we do not find a stronger

\footnotetext{
${ }^{14}$ This effect is not expected but we cannot untangle the effect from age and the effect from remaining lifetime. Our results point to agents as more averse to old technologies even when their lifespan is short.
} 
response in places in which this weight is larger (see column 5 of Table 4 ). ${ }^{15}$ We find the opposite: the price malus is small in these places with the largest NPP employment ratio. Second, we can use our analysis on persistence to discard the employment channel. Indeed, the news releases about the continuation of nuclear programmes occurred during the year 2012, and we show that such release is not followed by a rebound in housing markets (see Table 7 ): ${ }^{16}$ there is no significant difference in the demand shift even after the news release. Finally, we have found an effect around nuclear waste sites that are not susceptible to close down, and have a very low direct effect on local employment. Thus, we are confident that we can discard economic effects to explain changes in housing market prices.

We can compare our main estimate to the average decrease in residential prices around Fukushima nuclear plant. As a 20km exclusion zone was set around the plant, housing markets were frozen in the close vicinity of the plant. Managi and Tanaka (2014) show that an increase in radiation dose of $1 \mu S v / h$ decreases residential land value by $3.1 \%$. Only 8 out of 38 municipals in Fukushima prefecture have recorded a radiation level above $1 \mu S v / h$ after the accident (June and July 2011). For most areas located between 20 and $60 \mathrm{~km}$ away from Fukushima nuclear plant, the effect of radiation on residential land prices is lower that our estimate on prices of properties in the close vicinity of a nuclear plant in England or Wales.

To give an idea of the economic importance of the impact of Fukushima accident on English housing markets, we perform two back-of-the-envelope calculations. Using the volume of transactions in treated zones in 2010 as a starting point, and our difference-in-difference estimate of the Fukushima accident effect on the volume of transactions with LSOA fixed effects (column 2 of Table 3), we get that the annual loss in transactions' volume amounts to 164 million of Sterling pounds, ${ }^{17}$ i.e about $0.4 \%$ of the increase in nominal terms of the UK GDP in 2012. A rough calculation gives that Fukushima accident has reduced the value of the stock of properties nearby NPPs by 7.6 billion of Sterling pounds, this is equivalent to a $0.2 \%$ decrease of the value of the entire English housing stock. ${ }^{18}$ Obviously, these back-of-the-

\footnotetext{
${ }^{15}$ The closure of a nuclear power station may affect employment beyond its direct effect. However, as long as these spillovers are linear in the direct effect, our constructed ratio will be proportional to the expected aggregate effect. It could be, however, that spillovers are much larger when a NPP employs a large fraction of the individuals in a neighborhood.

${ }^{16}$ We can also construct for each nuclear power station the official date for its contract renewal with the State, and divide the treated period between pre- and post-announcement periods. Given that announcements were made around the same period, it would give the same results.

${ }^{17}$ Using the average volume of transactions per LSOA/month and the number of month/LSOA observations for 2010 from Table 2 , the calculation writes: $0.0340 * £ 400105.8 * 12064=$ $£ 164113796.6$

${ }^{18}$ Transactions in treated zones represent in average $5.8 \%$ of transactions in England and Wales recorded in Land Registry. According to the 2011 Census, 23.4 million of households live in England
} 
envelope calculations are measures of the hedge between the value of properties in at-risk zones after Fukushima and their counterfactual value under the assumption that these at-risk areas would have followed the same trend than control areas. This ignores the fact that housing markets' dynamics in control areas may also have been affected by Fukushima accident since housing markets in at-risk and safer areas are related together via households' location decisions.

\subsection{Interpretation}

The effect of the Fukushima incident on the English housing market results from a combination of (i) a shift in risk perception, (ii) the disamenity associated with additional nuclear risk and (iii) the housing market response to the shift in housing demand. While we cannot identify separately the contribution of these fundamentals, e.g., the elasticity of housing demand to risk perception, we describe these elements in the following lines.

We consider the following housing demand schedule $D(p)=\bar{D}(p)-v(r)$, where:

- $\bar{D}$ captures the observed housing characteristics and the local amenities. These elements are captured in the empirical specification by LSOA-fixed effects, transaction characteristics, access to schools in the output area, deprivation indices, housing stock, percentage of high-educated individuals, students, retired and region-specific trends.

- $r=E[C=1 \mid I]$ is the expected probability of a nuclear catastrophe, and $v$ is the valuation associated with such catastrophic risk.

This example is illustrative and we model the demand shift as a parallel shift, i.e., $v$ does not depend on prices. With heterogeneous agents and some correlation between access to information and housing demand, this hypothesis would be violated.

In parallel, we assume that there is a housing supply schedule $S(p, r)$. We keep its formulation general but we will impose some restrictive assumptions in the following lines.

Permanent shift in expectations With imperfect information on nuclear risk, the occurrence of a catastrophe should modify the information set that Bayesian agents use to establish their housing demand. Let us assume that the occurrence

and Wales. Assuming that the number of properties in England and Wales equals the number of households, and that the percentage of properties sold in treated zones in 2010 is as in the rest of the country, we consider that about 1.3 million of residential properties are located in treated zones. Using the average price of the transacted properties in treated zones in 2010 as the average price of properties in these zones, we do the following calculation $0.0325 * £ 179361.5 * 1.3 m \approx £ 7.6 b$. 
of a catastrophe is a permanent shock on agents' expectations: they are perfectly Bayesian and never forget about past realizations. Letting $I^{\prime}$ denote the new information set and assuming that all other amenities remain the same, the demand curve shifts downward by

$$
v(E[C=1 \mid I])-v\left(E\left[C=1 \mid I^{\prime}\right]\right) \approx \underbrace{-v^{\prime}(r)}_{\text {valuation }} \cdot \underbrace{\left[r^{\prime}-r\right]}_{\text {perception }} .
$$

In contrast, housing supply should be independent of revisions in $r$ : there is no gain for agents willing to sell their house to wait and the supply stock remains constant.

In this case, we represent the new equilibrium in figure 3 . The price drop entirely reflects the change in risk perception weighted by the household's risk aversion. If we interpret transactions in the housing market as small frictional adjustments to reach the new equilibrium, then the market liquidity and the number of transactions per month should not vary after the catastrophe.

Transitory shift in expectations If instead, the occurrence of a catastrophe is a transitory shock at least according to some agents' expectations, the housing supply schedule will be increasing, reflecting that some agents may refuse to sell their house below a certain price, accounting for the expected future price. We represent this equilibrium in Figure 4.

In contrast with the previous case, the drop in prices reflects the change in risk perception weighted by the household's risk aversion but also the elasticities of housing demand and supply (partly driven by the expectations in a future price recovery). In such scenario, if we interpret transactions in the housing market as small frictional adjustments to reach the new equilibrium, there will be fewer transactions after the catastrophe. Some households will refuse to sell their house given the current demand schedule, will wait for better opportunities thereby lowering the number of transactions.

Interpretation Our results indicate that the shift in expectations was permanent. Indeed, the relatively modest decrease in the number of transactions (1\%) compared to the price drop $(3.5 \%)$ points to a very low price elasticity of housing supply. This result stands in stark contrast with studies having documented a rest vacancy effect, i.e., households refusing to lower their prices waiting for future better opportunities (e.g., Bléhaut 2014).

The modest decrease in the number of transactions also implies that the price decrease essentially reflects the demand shift (and not elasticities of housing demand 
or supply coming from market imperfections or heterogeneities in risk valuations) as shown in Figure 4. One issue that we will not be able to tackle is that the demand shift is driven by (i) a shift in risk perception, (ii) the disamenity associated with additional nuclear risk. The large price decrease of about $3.5 \%$ may indicate that households have a very high disamenity from being exposed to nuclear risk, or that they have sharply modified their risk perception. We come back to this question in the next section. In the next lines, we rather investigate the robustness of our main estimates.

\subsection{Robustness checks}

In this section, we provide a series of robustness checks to show that our results are not driven by pre-treatment differential trends, the limited set of housing transactions' controls present in Land Registry or our treatment definition.

In a first robustness check, we test the parallel trends assumption of our differencein-difference approach. In order to do this, we restrict our analysis to the preFukushima period and we define a placebo experiment in which Fukushima would have occurred in March 2010. We then estimate specification (2), and replicate the main specification in Table 3, i.e., we look at prices around nuclear plants. ${ }^{19}$ As evident in Table 6, we do not find any relevant differential trends in the neighborhood of nuclear plants: when we add LSOA fixed effects, the difference-in-difference estimate between January 2007-February 2009, and March 2009-February 2011 is about -0.004 and non-significantly different from 0 .

In the second robustness check (see Table 10), we re-estimate specification (2) using Nationwide data instead of Land Registry data. We take advantage of the larger set of transaction controls and add the number of bedrooms, square meters, the construction date and the type of good (e.g., flat, Victorian house) to our original controls. Note, however, that due to the selection induced by the use of Nationwide data, we only run the specifications with LSOA fixed effects. The results are similar to the benchmark specification. There is a $3 \%$ price malus in neighborhoods close to active nuclear plants. The estimates remain quite precise in spite of the lower number of recorded transactions.

In a third robustness check (see Table 11), we test the sensitivity of our results to the addition of differential trends along some LSOA characteristics. Our results could be driven by a higher concern in zones that have more ecological concerns

\footnotetext{
${ }^{19} \mathrm{We}$ do not report the results of this placebo test for the number of transactions, the volume of transactions, and the estimates around nuclear waste sites, but the estimates are always noneconomically significant (results available on request).
} 
in general, and the neighborhoods of nuclear plants are potentially such zones. In column 1 of Table 11, we add the share of green votes during the 2010 election interacted with time dummies. We then add the income, employment, health, education and crime deprivation ranks interacted with time dummies (column 2). Finally, we add census controls (type of accommodation, high/medium/low education levels, occupational structure) interacted with time dummies in column 3. None of those controls modify our conclusions. ${ }^{20}$

In a fourth robustness check (see Table 12), we test the sensitivity of our results to other treatment definitions. We first redefine our treated zone (resp. control zones) as being between 0-15 km (resp. 15-100 km), 0-25 km (resp. 25-100 km) and $0-50 \mathrm{~km}$ (resp. $50-100 \mathrm{~km}$ ) from a nuclear plant and we report the results in columns 1, 2 and 3. Second, we consider a continuous treatment, i.e., the distance to the closest nuclear plant (see column 4). None of these specifications discard our conclusions drawn from the benchmark estimates.

\section{The demand shift and the distributional effects}

This section presents an analysis of the demand shift across different price quantiles, and an interpretation of these results.

\subsection{The demand shift across price quantiles and neighborhoods}

So far, we have analyzed the demand shift in the housing markets, but we have focused on the average effect.

We now run two separate analyses. In the first specification, we focus on the within-neighborhood distribution of prices and its evolution after Fukushima. In the second specification, we analyze the differences in price response across neighborhoods and we use three observable characteristics to define neighborhoods, their deprivation score, whether they are urban or rural and the existence of a green support.

In Table 5, we report the result of quantile regressions based on specification (2) with the LSOA fixed effects and the transaction controls. As in Table 3, we restrict our sample to the period January 2009 - September 2014.

The results are striking. There is a wide heterogeneity in the price response across quantiles. The $10 \%$-quantile effect is close to 0 while the $25 \%$ and median effects are around $-3.5-4 \%$, the $75 \%$ around $-5.5 \%$ and the $90 \%$ above $-7 \%$. There

\footnotetext{
${ }^{20}$ Controlling for i. the council taxes, ii. the number of open vacancies, or iii. the school performance does not alter our results (results available on request).
} 
is a strong compression in the distribution of prices in response to Fukushima: the shift in demand seems to be particularly pronounced for high-value goods. ${ }^{21}$

In Table 8, we report specification (2) with interaction terms between the effect and four neighborhood characteristics. In the first specification (column 1), we interact our treatment with a dummy for neighborhoods with a deprivation score above the median. In the second specification (column 2), we add an interaction with a dummy for being in a rural area. In the third specification (column 3), we add the support (in percentage points) for a local green candidate in the 2010 legislative elections. In the last specification (column 4), we replace the support for a local green candidate in the 2010 legislative elections by the turnout levels during this election. While there are large additional maluses for deprived (-3\%) and rural areas $(-2 \%)$ as well as areas with low turnout $(+3 \%$ for 10 additional points in turnout 2 standard deviations), we see no heterogeneity across neighborhoods with different green support.

These results are surprising in two dimensions. First, the price distribution within neighborhoods tilts towards the lower tail, but this shift is essentially seen in deprived areas, whether the indicator for being a deprived area is a rural dummy, a deprivation score or turnout during a legislative election. ${ }^{22}$

One way to see this phenomenon is to plot the pre- versus post-Fukushima distribution of transaction prices in treated versus control places, and to differentiate between deprived neighborhoods (see Figure 6) and non-deprived neighborhoods (see Figure 7). Transaction prices strongly respond in deprived areas, and this response is mostly explained by a shortage of high-price transactions. In both deprived and non-deprived areas, the malus due to the proximity of a power plant is essentially in the $0-20 \mathrm{~km}$ ring around NPPs before and after the accident, as shown in Figure 8.

Second, green vote does not seem to have any influence, while it could be correlated with two elements that intervene in the theoretical demand shift, i.e., the disamenity related to nuclear risk and the information set of voters. ${ }^{23}$ The general low level of green votes in England and Wales may explain this result.

\footnotetext{
${ }^{21}$ We do not report the results with the Nationwide data, but the conclusions are the same.

${ }^{22} \mathrm{We}$ observe similar heterogeneous effects in the neighborhoods of waste sites (results available upon request).

${ }^{23}$ In its platform, the Green Party specifies that "[the Green Party] will cancel construction of new nuclear stations and nuclear power will not be eligible for government subsidy; the Green Party opposes nuclear power generation and is particularly opposed to the construction of new nuclear power stations".
} 


\subsection{Interpretation}

There are three potential dimensions of heterogeneity across agents that may explain the observed differences in the demand shift across the different price quantiles, and across the different neighborhoods. First, agents may differ in their access to information both in the precision of their pre-disaster information on nuclear risk, and in their capacity to process the Fukushima signal. For instance, richer agents might lend special attention to the news release on Fukushima and better update their beliefs. Second, in spite of similar beliefs before and after the disaster, agents may differ in their valuation of the underlying nuclear risk and richer agents may attribute a higher value to a safe environment (low radiation doses). Third, agents may differ in their ability to influence political decisions and obtain compensations for living close to a nuclear plant.

We describe below how these dimensions of heterogeneity may fit with our results.

Valuation Let us assume that agents can be characterized by (i) a disamenity for nuclear risk - "nuclear fear", and (ii) a certain demand for high-price houses "wealth", but their access to information is similar (they estimate nuclear risk with some precision).

Before Fukushima, a simple selection process should have led the agents with low nuclear fear to live in the neighborhoods of nuclear plants, and agents with high nuclear fear to live outside of the danger zone. The distribution of housing prices would then reflect the distribution of wealth across these types.

After Fukushima, all agents similarly revise their priors on nuclear risks, and adjust their housing demand to this new valuation. If wealthy agents are the ones who are most adverse to nuclear risk, the few of them having accepted to live in the neighborhood of a nuclear plant should all strongly shift their housing demand downward, and the housing prices both within and across postcodes should strongly compress.

Our results are not consistent with this sole mechanism. While we do find some compression within postcodes, we find that non-deprived areas with high housing prices are less responsive.

Information In contrast with the previous mechanism, we assume now that agents can be characterized by (i) access to prior information - "nuclear awareness", and (ii) a certain demand for high-price houses - "wealth", but their nuclear fear is similar - all agents attribute a same malus to the neighborhoods of nuclear plants.

Before Fukushima, the same selection process would have driven agents with high 
nuclear awareness outside of the danger zone, and mostly agents with low awareness would remain in the close neighborhood of nuclear plants.

After Fukushima, agents with the lowest nuclear awareness would respond the most. This could explain why deprived areas are most responsive, but cannot really explain why the effect is mostly driven by the right tail of the price distribution.

Information externalities Let us assume, as in the first story, that agents are characterized by "nuclear fear" and "wealth", and that these two dimensions are positively correlated, i.e. rich agents usually care more about nuclear risk. Suppose that information is imperfect: it requires effort to be informed, e.g., invest in investigation for the local newspaper, and there exists strong externalities (the efforts of one agent have positive spillovers).

In such a world, some neighborhoods of nuclear plants that are essentially composed of poor agents would have a low nuclear fear in average, nobody would invest in information and the few rich agents would be imperfectly informed about nuclear risk. Rich neighborhoods instead would have high nuclear fear and would invest a lot in information.

After Fukushima, these rich neighborhoods do not respond because nuclear risk was already perfectly identified. In contrast, individuals in poor neighborhoods would respond because of their very imprecise priors, and individuals with the highest nuclear fear would react the most.

Political power Let us assume, as in the first stories, that agents are characterized by "nuclear fear" and "wealth", and that these two dimensions are positively correlated, i.e. rich agents usually care more about nuclear risk. Assume that rich neighborhoods have political power such as they can influence political decisions and get specific compensations to live in at-risk areas, for instance in the form of new schools, local tax rebates and infrastructure improvements.

After FNA, rich areas do not respond much since they get extra compensation for the increased risk they are exposed to. Agents in deprived areas would respond more as they do not get compensations, and within this group, rich agents would respond the most as they have higher nuclear fear.

We do not have any tests for the exact mechanism at play. However, there exist different theoretical channels which would generate predictions in line with our empirical observations. 


\section{Conclusion}

Fukushima accident was a salient industrial accident that has generated important reactions from policy makers and public opinions worldwide about industrial risk. Understanding how people react to such a rare event and how they update their beliefs about nuclear risk is of prime importance.

In this paper, we study how nuclear-risk perception in England and Wales has changed due to the Fukushima nuclear accident. To track changes in risk perception, we use a difference-in-difference strategy, and we compare housing prices and transaction volumes in at-risk areas to those in safe areas before and after Fukushima incident. In order to define at-risk areas in the UK, we relied on the Fukushima Daiichi evacuation process (Japanese Government, 2011) and defined a $20 \mathrm{~km}$ evacuation zone around each nuclear site. This piece of information was discussed worldwide in media, thus was available to individuals in England and Wales.

Results are striking: due to Fukushima accident a price malus of about $3.5 \%$ for properties close to nuclear plants is observed across a variety of specifications. This price effect is persistent throughout the post-Fukushima period. Our results are at odds with British stable support in favor of nuclear power as expressed by opinion polls before and after Fukushima, and may reflect the fact that only a minority of the overall population remains at risk ( $2 \%$ of the England and Wales territory).

In the UK context, we show evidence that this price malus can be interpreted as a change in nuclear-risk perception. Indeed, no policy has been triggered that could have had an asymmetric impact on local housing markets nearby nuclear sites. In the United Kingdom, changes in housing prices are not due to economic impacts such as expected losses in local employment, expected reductions in local-tax revenues etc. The continuation of the nuclear programme in the United Kingdom contrasts with those of most other countries which were either canceled, suspended or reappraised. The case of Germany, whose Chancellor Angela Merkel decided to exit nuclear power by 2022 , is the strongest example.

In addition, we find a much larger price decrease for high-value properties within neighborhoods, and we show that deprived zones in at-risk areas are more responsive to the accident. We offer two main explanations of these results. They all share the assumption that richer agents put a higher value on a safe environment. This assumption allows to explain the compression of the transaction prices distribution that we observe within neighborhoods. First, if rich areas have more information about nuclear power, priors in these areas will be more accurate, thus people will react less to the accident compared to deprived areas, and rich persons in deprived 
areas would react the most if they value more a safe environment. Second, if rich areas have some political power that allow them to obtain compensations for the increased (perceived) nuclear risk, housing prices in these areas would not react by much. 


\section{References}

Anselin, Luc and Nancy Lozano-Gracia, "Errors in variables and spatial effects in hedonic house price models of ambient air quality," Empirical Economics, 2008, $34(1), 5-34$.

Bauer, Thomas K., Sebastian Braun, and Michael Kvasnicka, "Distant Event, Local Effects? Fukushima and the German Housing Market," Ruhr Economic Papers August 2013.

Bezdek, Roger H. and Robert M. Wendling, "The impacts of nuclear facilities on property values and other factors in the surrounding communities," International Journal of Nuclear Governance, Economy and Ecology, 2006, 1 (1), $122-144$.

Bléhaut, Marianne, "How does a change in risk perception affect the housing market? Evidence from an industrial accident in France," Technical Report 2014.

Blomquist, Glenn, "The Effect of Electric Utility Power Plant Location on Area Property Value," Land Economics, 1974, 50 (1), pp. 97-100.

Carruthers, John I. and David Clark, "Valuing environmental quality: a spacebased strategy," Journal of Regional Science, 2010, 50 (4), 801-832.

Clark, David E., Lisa Michelbrink, Tim Allison, and William C. Metz, "Nuclear Power Plants and Residential Housing Prices," Growth and Change, 1997, 28 (4), 496-519.

Cohen, Jeffrey P. and Cletus C. Coughlin, "Spatial Hedonic Models Of Airport Noise, Proximity, And Housing Prices," Journal of Regional Science, 2008, 48 (5), 859-878.

Davis, Lucas W., "The Effect of Power Plants on Local Housing Values and Rents," The Review of Economics and Statistics, November 2011, 93 (4), 1391-1402.

Debrezion, Ghebreegziabiher, Eric Pels, and Piet Rietveld, "The Impact of Railway Stations on Residential and Commercial Property Value: A Metaanalysis," The Journal of Real Estate Finance and Economics, August 2007, 35 (2), 161-180.

Fink, Alexander and Thomas Stratmann, "U.S. housing prices and the Fukushima nuclear accident: To update, or not to update, that is the question," 
ICER Working Papers, ICER - International Centre for Economic Research June 2013.

Folland, Sherman T. and Robbin R. Hough, "Nuclear Power Plants and the Value of Agricultural Land," Land Economics, 1991, 67 (1), 30-36.

Gamble, Hays B. and Roger H. Downing, "Effects of nuclear power plants on residential property values," Journal of Regional Science, 1982, 22 (4), 457-478.

Gayer, Ted, James T. Hamilton, and W Viscusi, "Private Values Of Risk Tradeoffs At Superfund Sites: Housing Market Evidence On Learning About Risk," The Review of Economics and Statistics, 2000, 82 (3), 439-451.

Gibbons, Stephen, "Gone with the Wind: Valuing the Visual Impacts of Wind Turbines through House Prices," SERC Discussion Papers 0159, Spatial Economics Research Centre, LSE April 2014.

Greenstone, Michael and Justin Gallagher, "Does Hazardous Waste Matter? Evidence from the Housing Market and the Superfund Program," The Quarterly Journal of Economics, 2008, 123 (3), 951-1003.

Hanaoka, Chie, Hitoshi Shigeoka, and Yasutora Watanabe, "Do risk preferences change? Evidence from panel data before and after the great east Japan earthquake," Technical Report 2014.

Hughes, William T. and C. F. Sirmans, "Traffic externalities and single-family house prices," Journal of Regional Science, 1992, 32 (4), 487-500.

IEA, "Key World Energy Statistics," 2014.

Japanese Government, "Report of Japanese Government to the IAEA Ministerial Conference on Nuclear Safety: The Accident at TEPCO's Fukushima Nuclear Power Stations.," Technical Report 2011.

Kiel, Katherine A. and Katherine T. McClain, "House Prices during Siting Decision Stages: The Case of an Incinerator from Rumor through Operation," Journal of Environmental Economics and Management, March 1995, 28 (2), 241255.

_ and Michael Williams, "The impact of Superfund sites on local property values: Are all sites the same?," Journal of Urban Economics, January 2007, 61 (1), 170-192. 
Kivimäki, Mika and Raija Kalimo, "Risk perception among nuclear power plant personnel: a survey," Risk Analysis, 1993, 13 (4), 421-424.

Managi, Shunsuke and Kenta Tanaka, "Impact of a Disaster on Land Price: Evidence from Fukushima Nuclear Power Plant Accident," MPRA Paper 59358, University Library of Munich, Germany October 2014.

Muehlenbachs, Lucija, Elisheba Spiller, and Christopher Timmins, "The Housing Market Impacts of Shale Gas Development," Working Paper 19796, National Bureau of Economic Research January 2014.

Nelson, Jon P., "Three Mile Island and Residential Property Values: Empirical Analysis and Policy Implications," Land Economics, 1981, 57 (3), 363-372.

Poortinga, Wouter, Midori Aoyagi, and Nick F. Pidgeon, "Public perceptions of climate change and energy futures before and after the Fukushima accident: A comparison between Britain and Japan," Energy Policy, 2013, 62, 1204 $-1211$.

Slovic, Paul, "Perception of risk," Science, 1987, 236 (4799), 280-285.

Viscusi, W. Kip and James T. Hamilton, "Are Risk Regulators Rational? Evidence from Hazardous Waste Cleanup Decisions," American Economic Review, 1999, 89 (4), 1010-1027.

Weightman, Mike, "Japanese earthquake and tsunami: Implications for the UK nuclear industry. Final Report," Technical Report, Office for Nuclear Regulation 2011.

Zhu, Hongjia, Yongheng Deng, Rong Zhu, and Xiaobo He, "Fear of Nuclear Power? Evidence from Fukushima Nuclear Accident and Land Markets in China," 2015 . 


\section{Figures and tables}

Figure 1. Map of nuclear power plants and nuclear waste sites.

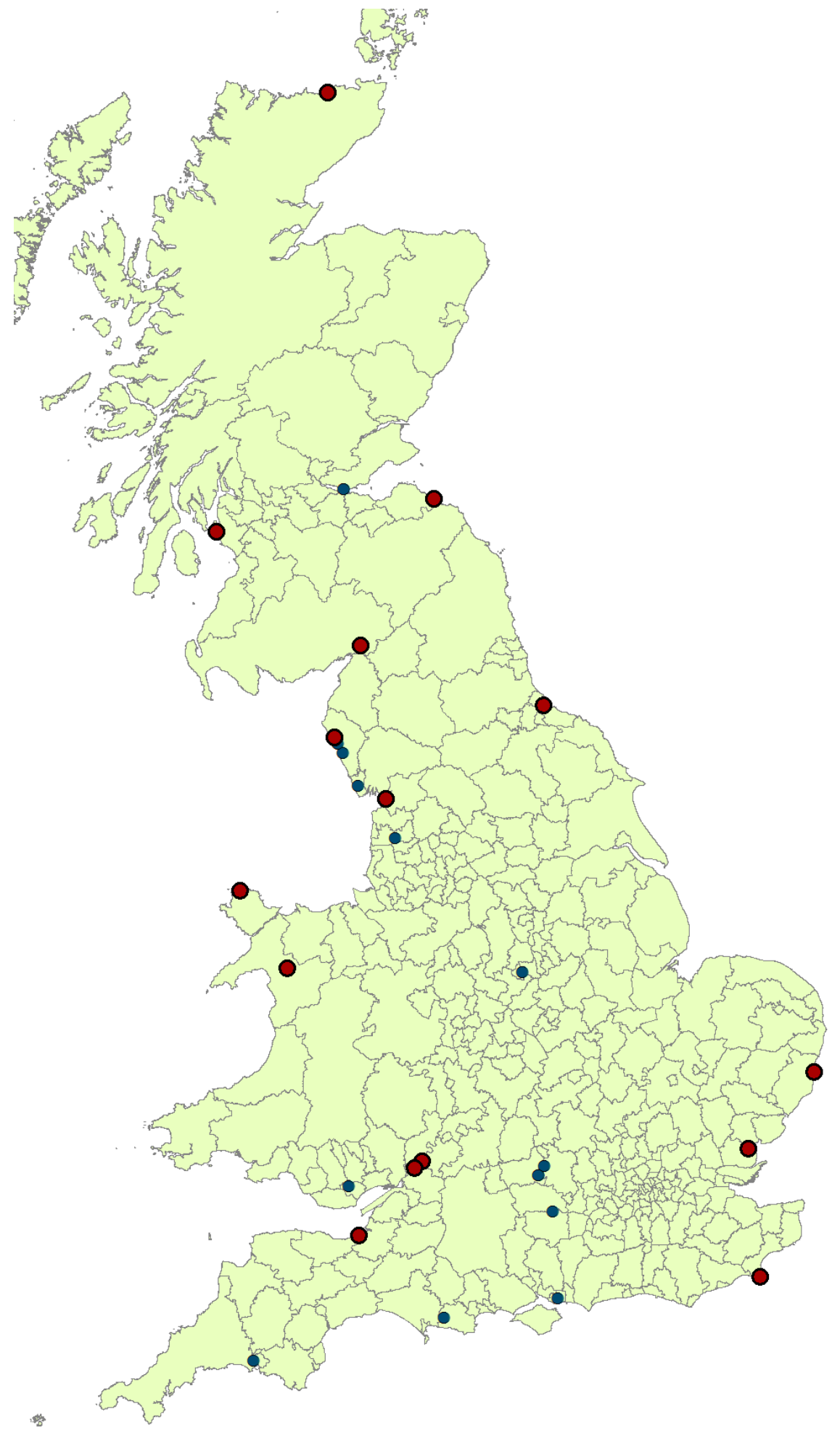

Nuclear plants (large red dots) and nuclear waste sites (small blue dots) in the United Kingdom (2012). 
Figure 2. Treated and control groups around nuclear plants $P_{1}, P_{2}$ and $P_{3}$.

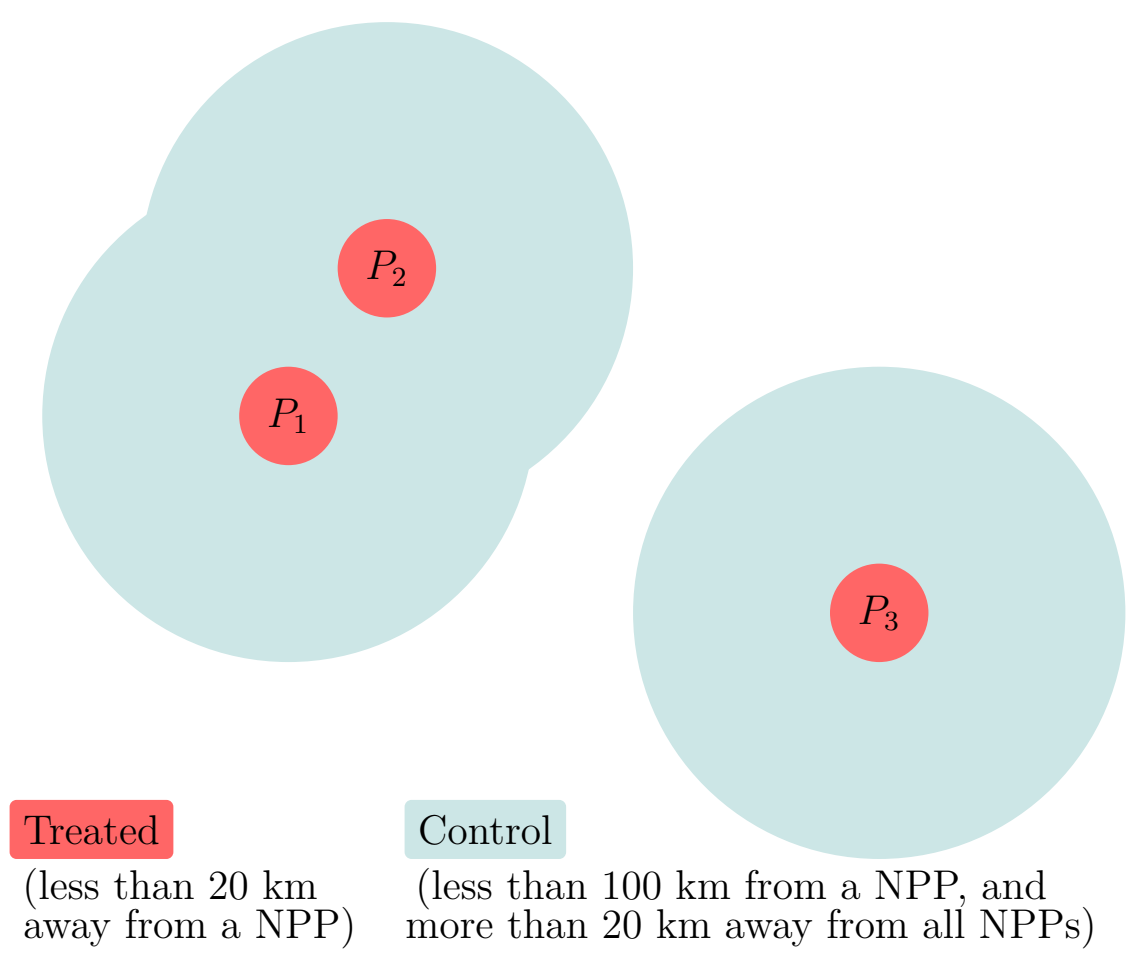

Figure 3. Housing market equilibrium (permanent belief revision).

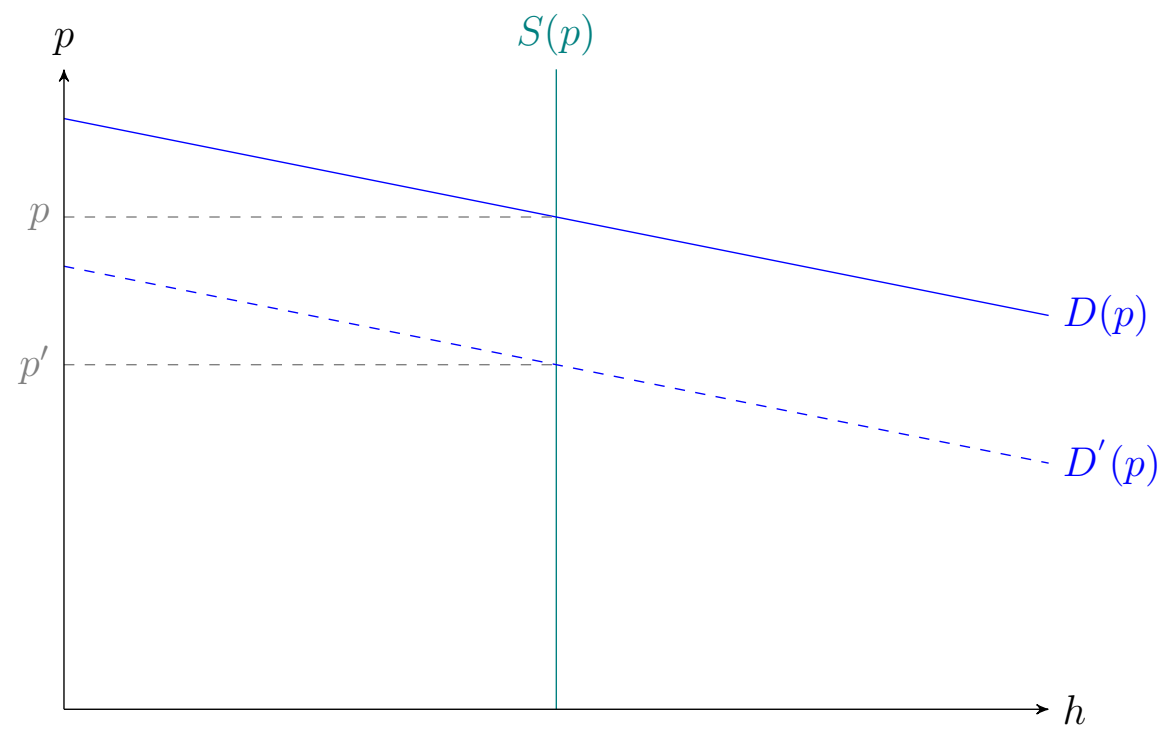


Figure 4. Housing market equilibrium (transitory belief revision).

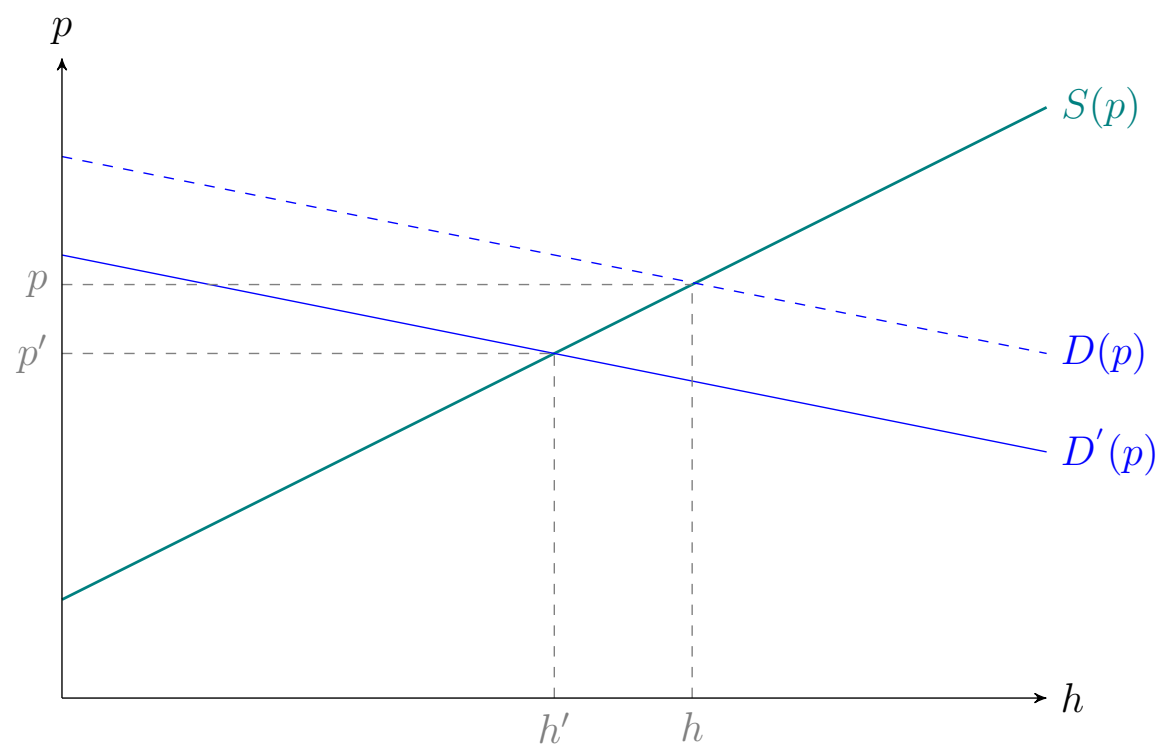

Figure 5. Average transaction prices as a function of distance to nuclear plants and waste sites.

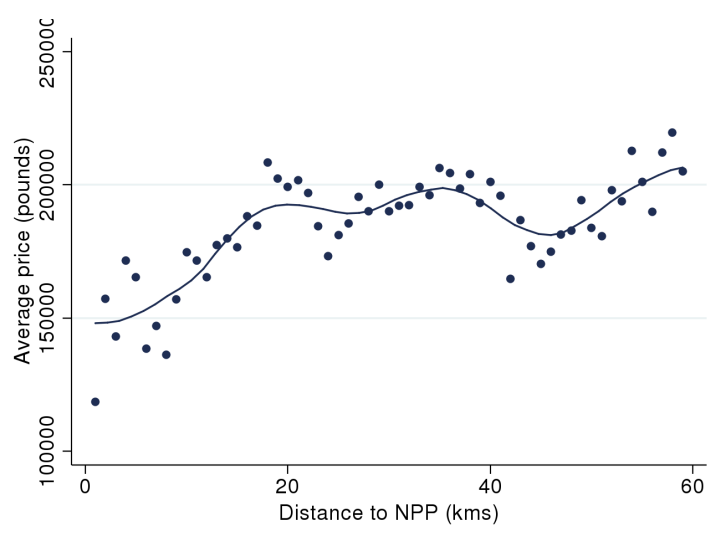

(a) Nuclear Plant.

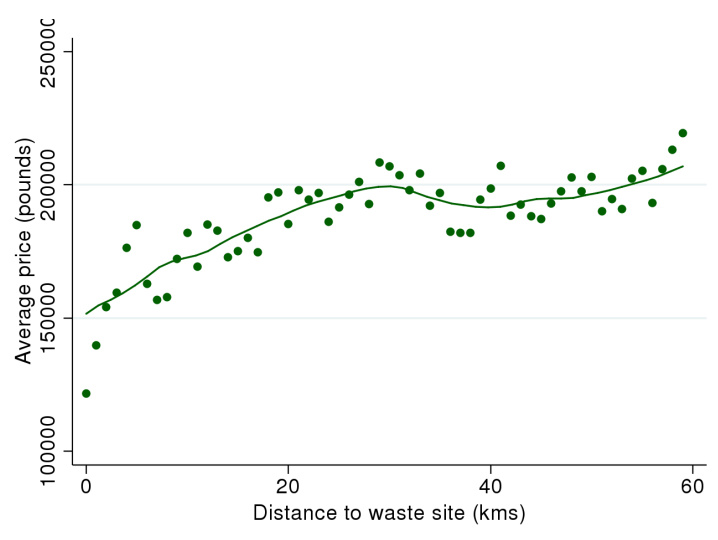

(b) Waste site.

Note: these figures display the average prices as a function of distance to nuclear plants (left panel) and waste sites (right panel) over the period January 2007-September 2014. 
Figure 6. Distributions of prices for deprived neighborhoods before and after Fukushima in treated (teal) and control zones (black).

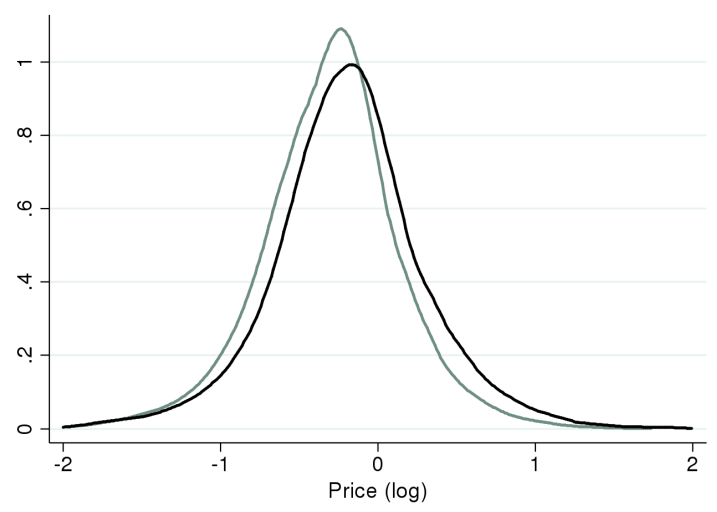

(a) Before.

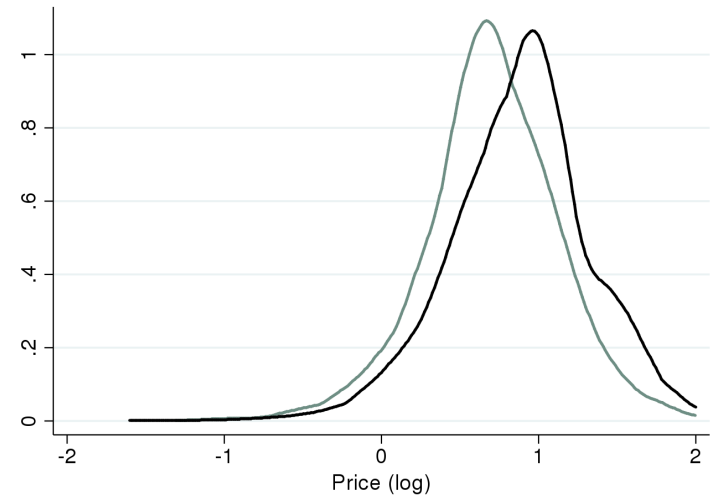

(b) After.

Note: these figures display the distribution of prices before (left panel) and after (right panel) the Fukushima accident for areas with a deprivation score above the median. Prices are in logarithms and cleaned for housing characteristics and area fixed effects.

Figure 7. Distributions of prices for non-deprived neighborhoods before and after Fukushima in treated (teal) and control zones (black).

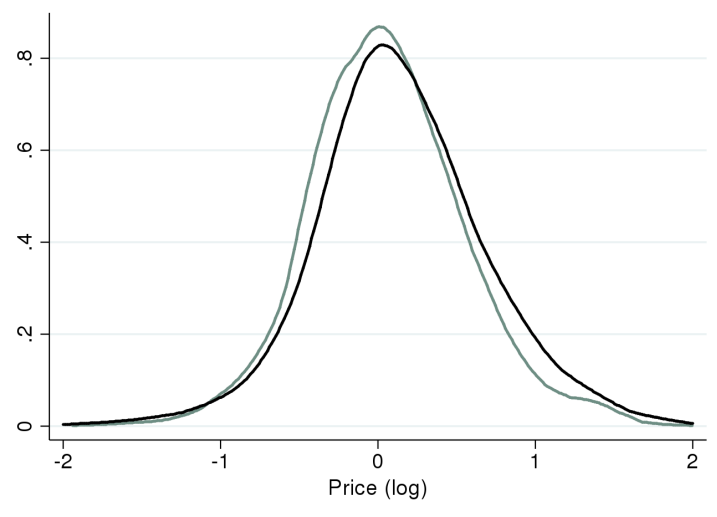

(a) Before.

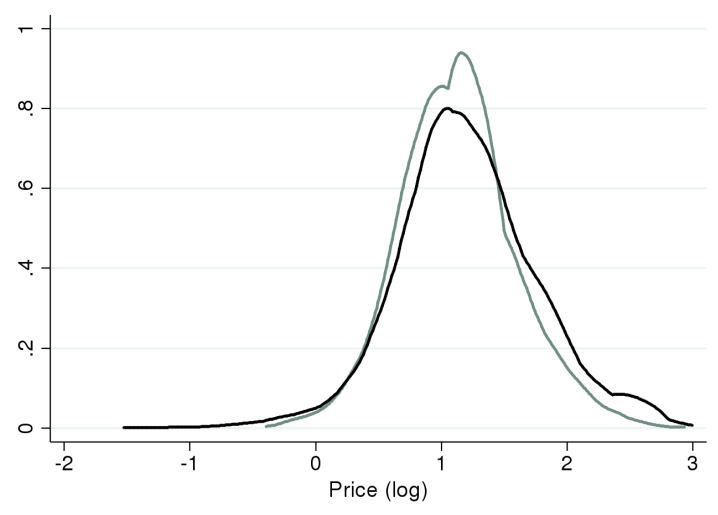

(b) After.

Note: these figures display the distribution of prices before (left panel) and after (right panel) the Fukushima accident for areas with a deprivation score below the median. Prices are in logarithms and cleaned for housing characteristics and area fixed effects. 
Figure 8. Average transaction prices as a function of distance to nuclear plants for deprived and non-deprived neighborhoods before (blue) and after (red) Fukushima.

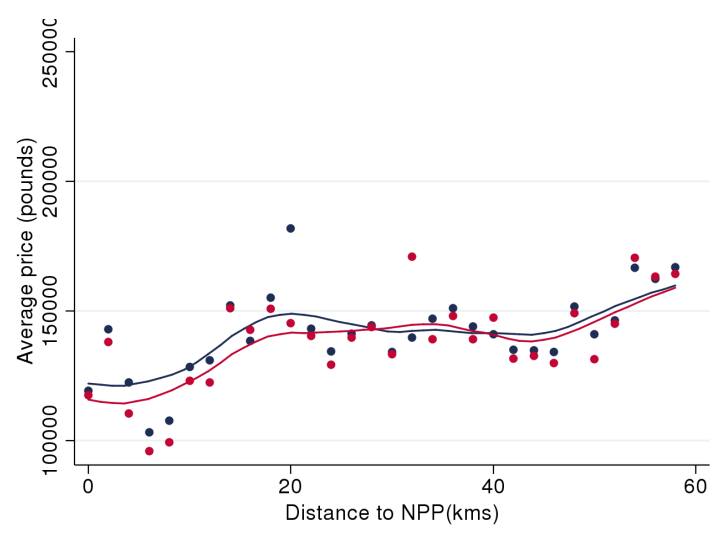

(a) Deprived.

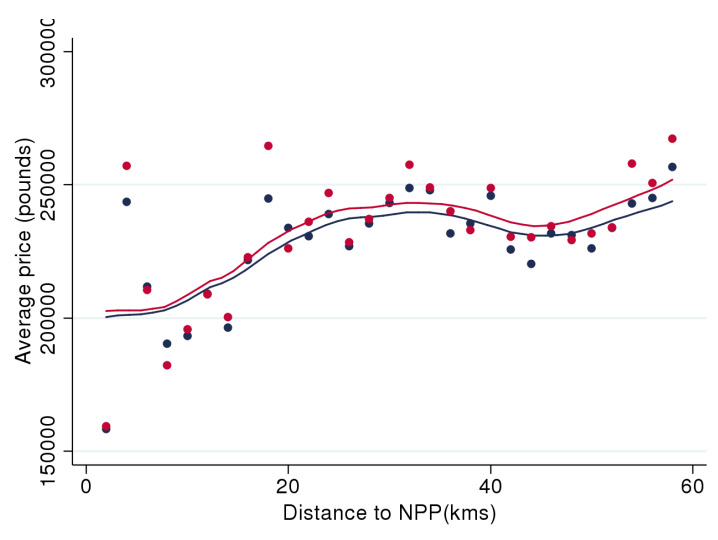

(b) Non-deprived.

Note: these figures display the average prices as a function of distance to nuclear plants in deprived neighborhoods (left panel) and non-deprived neighborhoods (right panel) over the period January 2007-March 2011 (blue) and March 2011-September 2014 (red). 


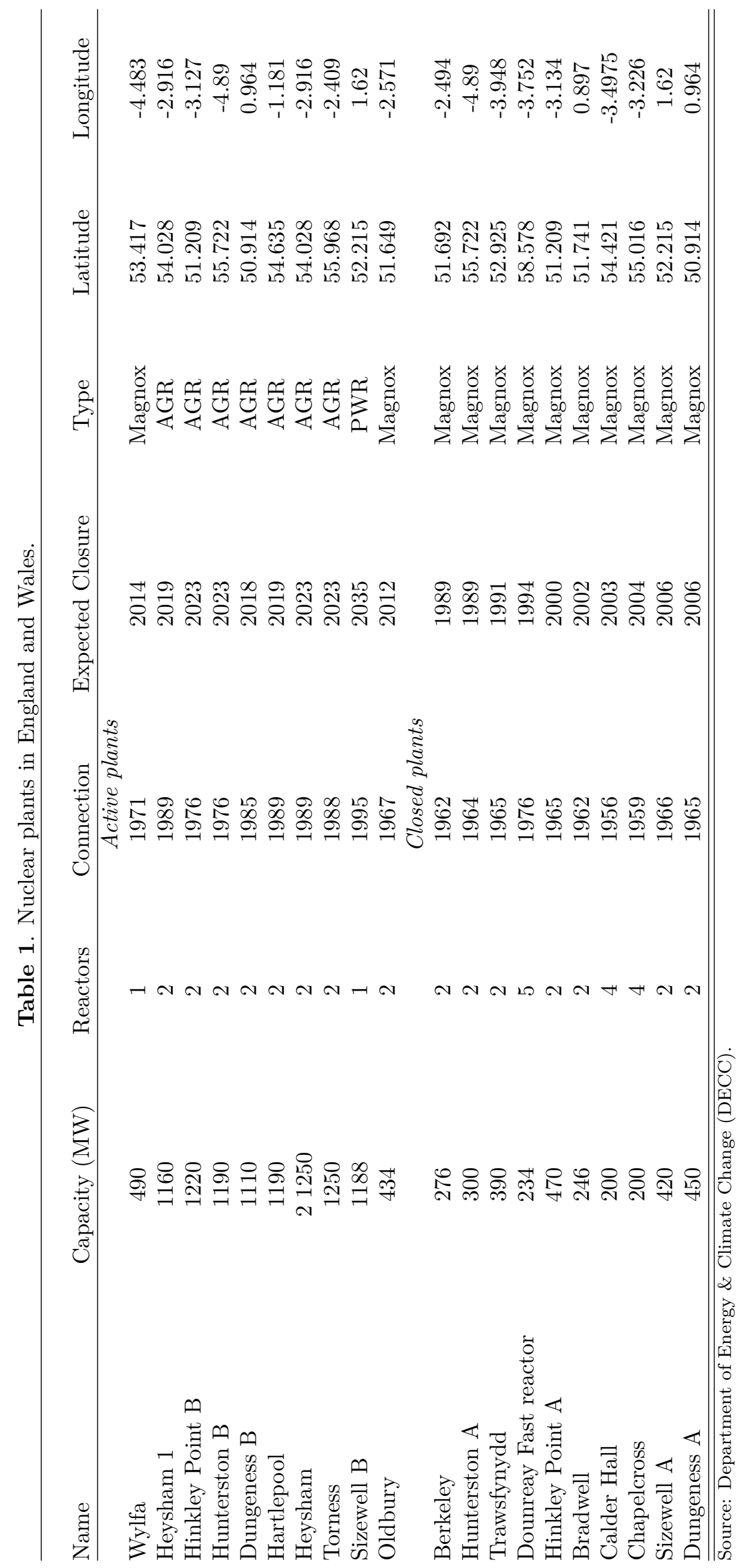


Table 2. Descriptive statistics in 2010.

\begin{tabular}{|c|c|c|c|c|c|}
\hline Sample & All & $T_{n p}=1$ & $T_{n p}=0$ & $T_{w s}=1$ & $T_{w s}=0$ \\
\hline$\overline{\text { Observations }}$ & 308,326 & 12,064 & 207,493 & 32,440 & 133,247 \\
\hline \multicolumn{6}{|c|}{ Housing market } \\
\hline Volume of transactions ${ }^{\dagger}$ & 514542.0 & 400105.8 & 541658.6 & 390673.9 & 533633.8 \\
\hline Average price ${ }^{\dagger}$ & 226297.8 & 179361.5 & 238280.8 & 177173.9 & 233955.0 \\
\hline Number of transactions & 2.169 & 2.157 & 2.167 & 2.146 & 2.173 \\
\hline fraction of new buildings & 0.040 & 0.045 & 0.038 & 0.039 & 0.040 \\
\hline fraction of flats & 0.158 & 0.089 & 0.187 & 0.096 & 0.167 \\
\hline \multicolumn{6}{|c|}{ Deprivation scores } \\
\hline Income rank & .533 & .525 & .520 & .535 & .534 \\
\hline Employment rank & .533 & .470 & .530 & .492 & .540 \\
\hline Barriers to housing rank & .503 & .609 & .472 & .595 & .493 \\
\hline \multicolumn{6}{|c|}{ Distance to nuclear facilities } \\
\hline Distance to plants & 80.59 & 13.71 & 65.56 & 59.28 & 82.18 \\
\hline Distance to waste sites & 52.82 & 13.62 & 53.70 & 12.30 & 56.35 \\
\hline
\end{tabular}

$\overline{\mathrm{A} \text { unit of observation is a month/LSOA. The deprivation scores are the percentile in the distribution over all the }}$ LSOAs in England. A rank of 1 means that the LSOA has the lowest score in England. ${ }^{\dagger}$ : All monetary variables are expressed in Sterling pounds. $T_{n p}\left(\operatorname{resp} . T_{w s}\right)$ is equal to 1 for all LSOAs whose centroid is within the potential evacuation zone of a nuclear power plant (resp. nuclear waste site), and to 0 for LSOAs in a band of $20-100 \mathrm{~km}$. 
Table 3. Effect of Fukushima on the housing market.

PANEL A: Nuclear plants

\begin{tabular}{lccc} 
& $(1)$ & $(2)$ & $(3)$ \\
\hline Price & $-.0379^{* * *}$ & $-.0241^{* * *}$ & $-.0325^{* * *}$ \\
& $(.0033)$ & $(.0021)$ & $(.0018)$ \\
Number of transactions & .00162 & $-.0098^{* * *}$ & $-.0136^{* * *}$ \\
& $(.0040)$ & $(.0037)$ & $(.0039)$ \\
& & & \\
Volume of transactions & $-.0363^{* * *}$ & $-.0340^{* * *}$ & $-.0462^{* * *}$ \\
& $(.0054)$ & $(.0044)$ & $(.0044)$ \\
& & & \\
Observations & $1,754,282$ & $1,754,282$ & $1,577,723$ \\
Controls (housing characteristics) & & & Yes \\
LSOA fixed effects & & Yes & Yes
\end{tabular}

PANEL B: Nuclear waste sites

\begin{tabular}{lccc} 
& $(1)$ & $(2)$ & $(3)$ \\
\hline Price & $-.0180^{* * *}$ & $-.0146^{* * *}$ & $-.0193^{* * *}$ \\
& $(.0027)$ & $(.0017)$ & $(.0016)$ \\
Number of transactions & & & \\
& -.00122 & $-.0106^{* * *}$ & $-.0137^{* * *}$ \\
& $(.0033)$ & $(.0030)$ & $(.0034)$ \\
Volume of transactions & & & \\
& $-.0 .0192^{* * *}$ & $.0252^{* * *}$ & $.0331^{* * *}$ \\
& $(.0044)$ & $(.0036)$ & $(.0039)$ \\
Observations & & & $1,429,256$ \\
Controls (housing characteristics) & $1,600,981$ & $1,600,981$ & Yes \\
LSOA fixed effects & & & Yes
\end{tabular}

$\overline{\text { Each cell displays the result of a separate regression (specification (2)). We only report the Difference-in-Difference }}$ coefficient, i.e. the coefficient before the treatment (LSOA centroid less than $20 \mathrm{~km}$ from a nuclear plant) interacted with a dummy for post-Fukushima. Robust standard errors in parentheses are clustered at the plant level. ${ }^{* * *}$ : $p<0.01,{ }^{* *}: p<0.05,{ }^{*}: p<0.1$. The unit of observation is a LSOA/month. All specifications include month/zone dummies which clean for all time variations in the $100 \mathrm{~km}$-neighborhood of any nuclear plant. 


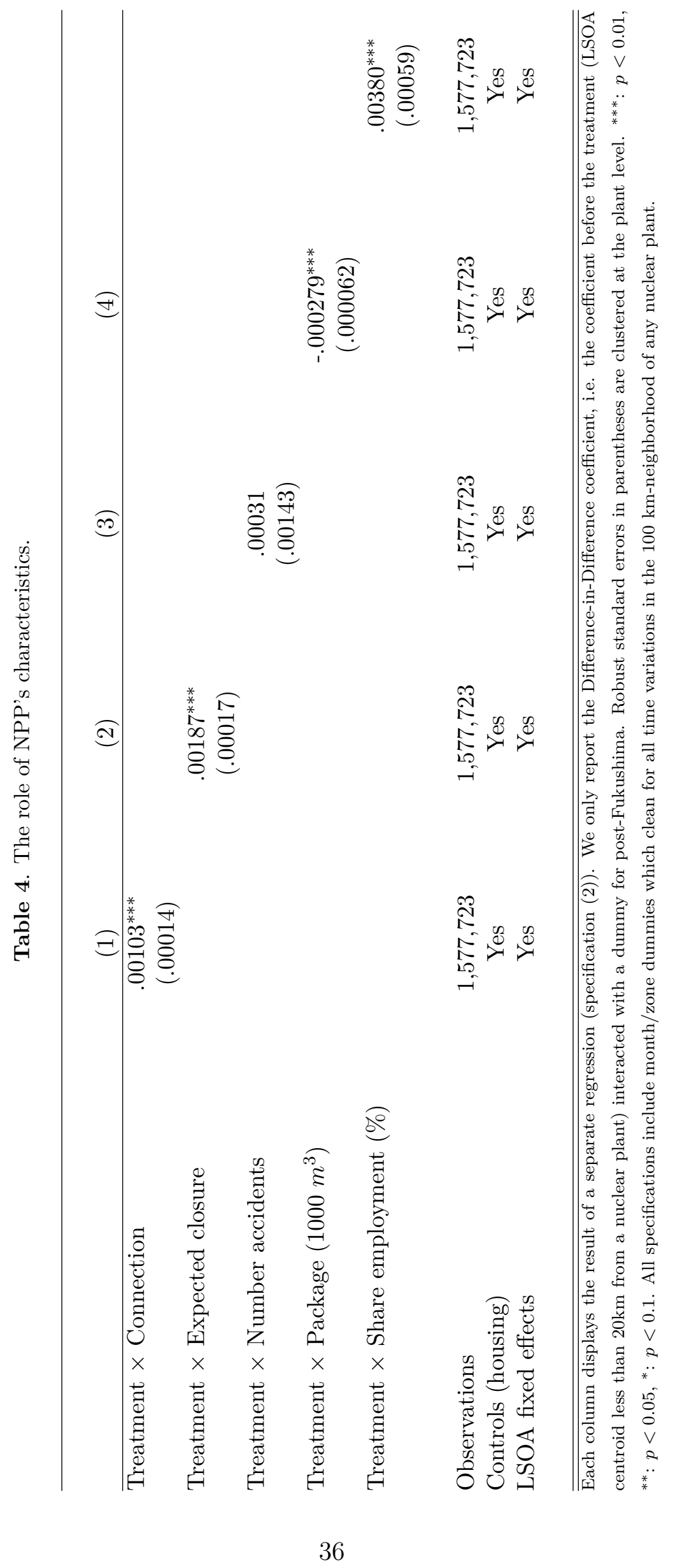


Table 5. Effect of Fukushima on the housing market - Quantile regressions.

\begin{tabular}{lccccc}
\hline & & & & & \\
Quantiles & .10 & .25 & .50 & .75 & .90 \\
\hline Price & -.00925 & $-.0405^{* * *}$ & $-.0332^{* * *}$ & $-.0565^{* * *}$ & $-.0710^{* * *}$ \\
& $(.0120)$ & $(.0093)$ & $(.0087)$ & $(.0110)$ & $(.0175)$ \\
Observations & 158,319 & 158,319 & 158,319 & 158,319 & 158,319 \\
Controls (housing) & Yes & Yes & Yes & Yes & Yes \\
\hline
\end{tabular}

$\overline{\text { Each cell displays the result of a separate quantile regression (specification (2)). We only report the Difference-in- }}$ Difference coefficient, i.e. the coefficient before the treatment (LSOA centroid less than 20km from a nuclear plant) interacted with a dummy for post-Fukushima. Robust standard errors in parentheses are clustered at the plant level. ${ }^{* * *}: p<0.01,^{* *}: p<0.05,{ }^{*}: p<0.1$. The unit of observation is a transaction. All specifications include month/zone dummies which clean for all time variations in the $100 \mathrm{~km}$-neighborhood of any nuclear plant. For computational purposes, we only keep a random subsample of the whole sample (10\%).

Table 6. Pre-treatment differential trends.

\section{Nuclear plants}

(1)

$-.0036$

$(.0053)$

740,020

.0010

$(.0034)$

Observations

Controls (housing characteristics)

740,020

LSOA fixed effects

Yes

Yes

$\overline{\text { Each cell displays the result of a separate regression (specification (2)). We only report the Difference-in-Difference }}$ coefficient, i.e. the coefficient before the treatment (LSOA centroid less than $20 \mathrm{~km}$ from a nuclear plant) interacted with a dummy equal to 0 between January 2007 and February 2009, and 1 between March 2009 and February 2011. Robust standard errors in parentheses are clustered at the plant level. ${ }^{* * *}: p<0.01,{ }^{* *}: p<0.05,{ }^{*}: p<0.1$. The unit of observation is a LSOA/month. All specifications include month/zone dummies which clean for all time variations in the $100 \mathrm{~km}$-neighborhood of any nuclear plant. 
Table 7. Persistence of the Fukushima effect.

\begin{tabular}{lcc}
\hline PANEL A: & $(1)$ & $(2)$ \\
Price & $-.0318^{* * *}$ & $-.0218^{* * *}$ \\
\hline Treatment $(03 / 11-11 / 12)$ & $(.0041)$ & $(.0022)$ \\
& $-.0345^{* * *}$ & $-.0349^{* * *}$ \\
Treatment $(12 / 12-12 / 13)$ & $(.0053)$ & $(.0027)$ \\
& & \\
Observations & $1,556,208$ & $1,399,234$ \\
Controls (housing characteristics) & & Yes \\
LSOA fixed effects & & Yes \\
\hline
\end{tabular}

PANEL B:

Number of transactions

(1)

(2)

Treatment (03/11-11/12)

$-.0116^{* *}$

$-.0080^{*}$

Treatment (12/12-12/13)

$(.0048)$

$(.0046)$

$-.0058$

$-.0161^{* * *}$

$(.0058)$

$(.0057)$

Observations

$1,551,687$

$1,395,612$

Controls (housing characteristics)

Yes

LSOA fixed effects

Yes

$\overline{\text { Each cell displays the result of a separate regression (specification (2)). We only report the Difference-in-Difference }}$ coefficient, i.e. the coefficient before the treatment (LSOA centroid less than $20 \mathrm{~km}$ from a nuclear plant) interacted with a dummy for post-Fukushima. Robust standard errors in parentheses are clustered at the plant level. $* * *$ : $p<0.01,{ }^{* *}: p<0.05,{ }^{*}: p<0.1$. All specifications include month/zone dummies which clean for all time variations in the $100 \mathrm{~km}$-neighborhood of any nuclear plant. 
A Additional tables and figures 


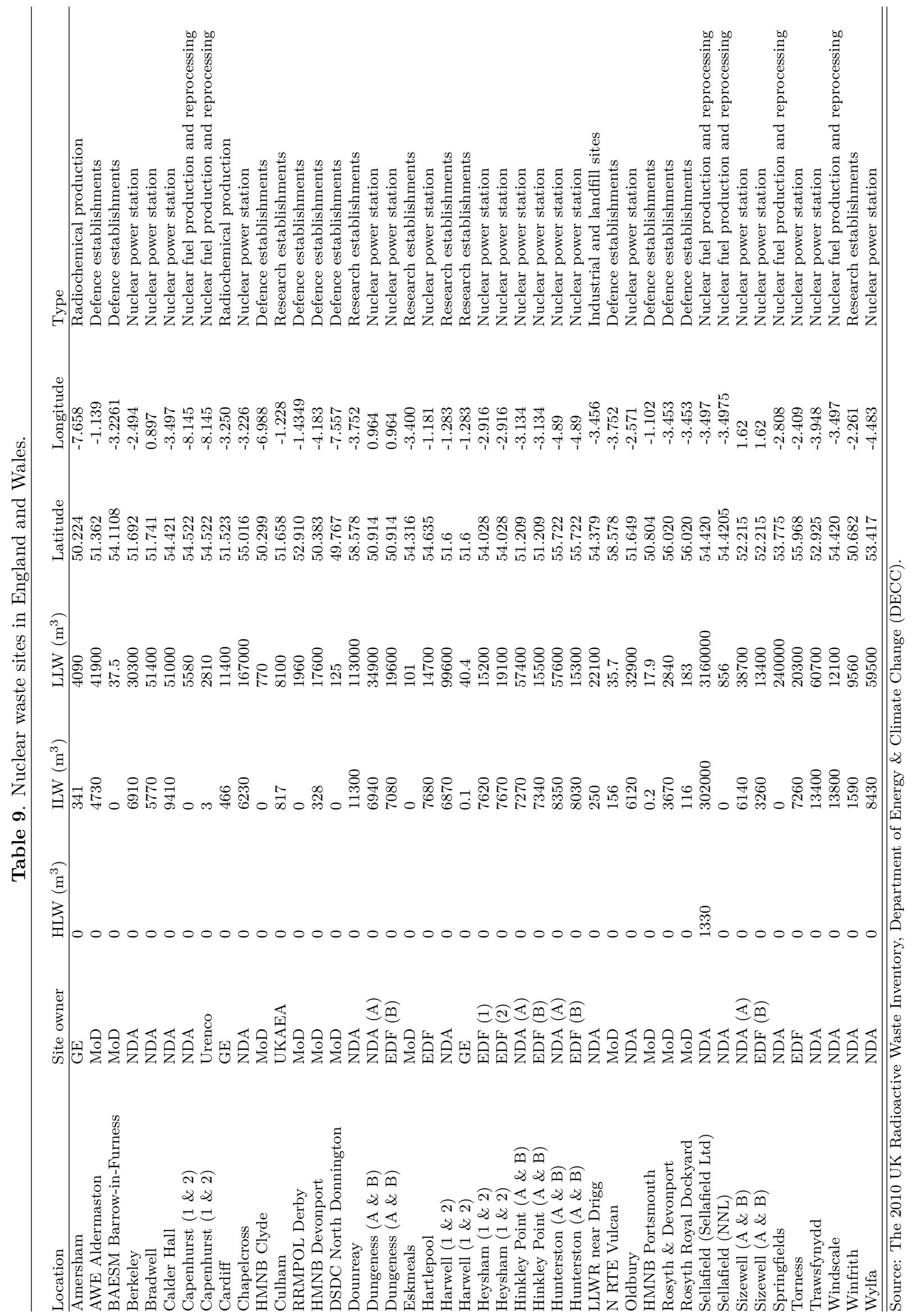


Table 10. Effect of Fukushima on the housing market - Nationwide data.

\section{PANEL A: Nuclear plants}

Price

$-.0319^{* * *}$

$-.0250^{* *}$

Observations

402,113

402,113

Controls (housing characteristics)

LSOA fixed effects

$\begin{array}{ll} & \text { Yes } \\ \text { Yes } & \text { Yes }\end{array}$

\section{PANEL B: Nuclear waste sites}

(1)

$-.0157^{* * *}$

Price

380,886

Observations

Controls (housing characteristics)

LSOA fixed effects
Yes

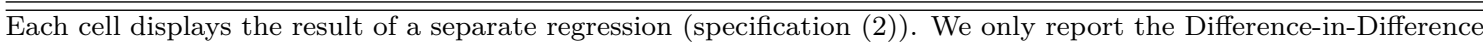
coefficient, i.e. the coefficient before the treatment (LSOA centroid less than $20 \mathrm{~km}$ from a nuclear plant) interacted with a dummy for post-Fukushima. Robust standard errors in parentheses are clustered at the plant level. ${ }^{* * *}$ : $p<0.01,^{* *}: p<0.05,^{*}: p<0.1$. The unit of observation is a transaction. All specifications include month/zone dummies which clean for all time variations in the $100 \mathrm{~km}$-neighborhood of any nuclear plant. 
Table 11. Effect of Fukushima on the housing market - robustness checks with additional controls.

\begin{tabular}{lccc}
\hline PANEL A: Nuclear plants & $(1)$ & $(2)$ & $(3)$ \\
\hline Price & $-.0449^{* * *}$ & $-.0318^{* * *}$ & $-.0293^{* * *}$ \\
& $(.0024)$ & $(.0024)$ & $(.0024)$ \\
& & & \\
Observations & 727,032 & 727,032 & 727,032 \\
Controls (green votes) & Yes & Yes & Yes \\
Controls (deprivation indices) & & Yes & Yes \\
Controls (census) & & & Yes \\
Controls (housing characteristics) & Yes & Yes & Yes \\
LSOA fixed effects & Yes & Yes & Yes \\
& & &
\end{tabular}

PANEL B: Nuclear waste sites

\begin{tabular}{lccc} 
& $(1)$ & $(2)$ & $(3)$ \\
\hline Price & $-.0421^{* * *}$ & $-.0318^{* * *}$ & $-.0290^{* * *}$ \\
& $(.0023)$ & $(.0023)$ & $(.0023)$ \\
Observations & & & \\
Controls (green votes) & 607,793 & 607,793 & 607,793 \\
Controls (deprivation indices) & Yes & Yes & Yes \\
Controls (census) & & Yes & Yes \\
Controls (housing characteristics) & & & Yes \\
LSOA fixed effects & Yes & Yes & Yes \\
& Yes & Yes & Yes
\end{tabular}

$\overline{\text { Each cell displays the result of a separate regression (specification (2)). We only report the Difference-in-Difference }}$ coefficient, i.e. the coefficient before the treatment (LSOA centroid less than 20km from a nuclear plant) interacted with a dummy for post-Fukushima. Robust standard errors in parentheses are clustered at the plant level. ${ }^{* * *}$ : $p<0.01,{ }^{* *}: p<0.05,{ }^{*}: p<0.1$. All specifications include month/zone dummies which clean for all time variations in the $100 \mathrm{~km}$-neighborhood of any nuclear plant. 
Table 12. Effect of Fukushima on the housing market - robustness checks with other treatment definitions.

\begin{tabular}{lcccc}
\hline $\begin{array}{l}\text { PANEL A: Nuclear plants } \\
\text { Price }\end{array}$ & $(1)$ & $(2)$ & $(3)$ & $(4)$ \\
\hline Treatment $(0-15 \mathrm{~km})$ & $\left(.0248^{* * *}\right.$ & & \\
& & $-.0338^{* * *}$ & & \\
Treatment $(0-25 \mathrm{~km})$ & $(.0015)$ & & \\
& & $-.0362^{* * *}$ & \\
Treatment $(0-40 \mathrm{~km})$ & & $(.0011)$ & \\
& & & $.00015^{* * *}$ \\
Distance $(\mathrm{km})$ & & & $(.00001)$ \\
& & & & \\
& & & & \\
Observations & & & & \\
Controls (housing characteristics) & Yes & Yes & Yes & Yes \\
LSOA fixed effects & Yes & Yes & Yes & Yes \\
& & & & \\
\hline
\end{tabular}

PANEL B: Nuclear waste sites

Price (1)

Treatment $(0-15 \mathrm{~km}) \quad-.0220^{* * *}$

$(.0020)$

Treatment $(0-25 \mathrm{~km})$

Treatment $(0-40 \mathrm{~km})$

Distance $(\mathrm{km})$

$(2)$

$\begin{array}{cccc} & -.0275^{* * *} & & \\ & (.0014) & & \\ & & -.0333^{* * *} & \\ & & (.0010) & \\ & & & .00057^{* * *} \\ & & & \\ & & & \\ 1,429,256 & 1,429,256 & 1,429,256 & 2,253,942 \\ \text { Yes } & \text { Yes } & \text { Yes } & \text { Yes } \\ \text { Yes } & \text { Yes } & \text { Yes } & \text { Yes } \\ & & & \end{array}$

Observations

Controls (housing characteristics)

LSOA fixed effects

Yes

Each column displays the result of a separate regression (specification (2)). We only report the Difference-inDifference coefficient, i.e. the coefficient before the treatments interacted with a dummy for post-Fukushima. Robust standard errors in parentheses are clustered at the plant level. ${ }^{* * *}: p<0.01,{ }^{* *}: p<0.05,{ }^{*}: p<0.1$. All specifications include month/zone dummies which clean for all time variations in the $100 \mathrm{~km}$-neighborhood of any nuclear plant. 


\section{B Data sources}

Nationwide Nationwide is the second largest mortgage provider in the United Kingdom, covering about $13-15 \%$ of the market (in volumes).

As a consequence, the sample of transactions is substantially smaller than Land Registry. The percentage of Land Registry transactions in Nationwide is 10.19, 10.46, 10.62, 9.63, 10.42, 16.19 and 16.55 between 2007 and 2013. The huge increase in 2012 relates to Nationwide strategy to cut fees. While the share of transactions varies with time, it is important to verify that such changes are not correlated with the treatment: the ratio of transactions included in Nationwide increases between 2007-2011 and 2012-2013 in similar proportions in treated (less than 20 kilometers from a nuclear plant) and non-treated zones.

Nationwide mostly covers small transactions, and these lower price quantiles are slightly over-represented. As before, however, the bias is very similar in treated and non-treated zones.

The Nationwide dataset includes a wide range of controls for the property characteristics (e.g., the construction date, the number of bedrooms, bathrooms, garages, the square meters or heating facilities), and these controls alleviate the main issue with Land Registry, i.e., the lack of individual-transaction controls. Accordingly, we mostly use Nationwide data such as to clean for within-LSOA compositional effects.

Local taxes We collect the Average Council Tax per Dwelling that is available at the Billing authority (BA) on the Department for Communities and Local Government website. We then link each to a LSOA. In parallel, we construct the number of properties assigned to each council tax band for each domestic property type in each geographic area (LSOA). Council tax bands define eight valuation bands (nine bands in Wales), i.e., A: Up to 40,000, B: 40,001 up to 52,000, C: 52,001 up to 68,000, D: 68,001 up to 88,000, E: 88,001 up to 120,000, F: 120,001 up to 160,000, G: 160,001 up to 320,000 , H: 320,001 and above, on the basis of the domestic property value on 1st April 1991 (1st April 2003 in Wales).

School performance We collect information about the performance of schools provided by the Department of Education for the period 2009-2013 and we construct:

- a proxy for each school size (number of pupils per school),

- and proxies for students' quality, i.e., the Average Point Score for each one of the stages (KS2, KS4, KS5). 
Job Vacancies The information about the number of job vacancies by LSOA is available since 2004 up to November 2012 at the LSOA level. It is created on the basis of reports from Job Centres. ${ }^{24}$ We thus generate the number of total vacancies in each LSOA that we normalize by the number of prime-age working adults.

Census From the census 2011, we reconstruct in each LSOA the average quality of accommodation, the average age of inhabitants, the number of schooling years, and the LSOA composition in terms of ethnicity and religion.

Green Votes The information on the vote share obtained by the Green Party on the UK Parliament general election of 6 May 2010 was downloaded from:

http://www.electoralcommission.org.uk/our-work/our-research/electoral-data.

Deprivation The English Indices of Deprivation (2010) were constructed by the Social Disadvantage Research Centre at the Department of Social Policy and Social Work at the University of Oxford. The index is a weighted average of several subindices for each output area (Income Deprivation, 22.5\%, Employment Deprivation, 22.5\%, Health Deprivation and Disability, 13.5\%, Education, Skills and Training Deprivation, 13.5\%, Barriers to Housing and Services, 9.3\%, Crime, 9.3\%, Living Environment Deprivation, 9.3\%).

The Income Deprivation measure sums the number of adults and children in families with Income Support, income-based Jobseeker's Allowance, Pension Credit (Guarantee) or Child Tax Credit. Asylum seekers in England in receipt of subsistence support, accommodation support, or both are also included.

The Employment Deprivation measure sums the number of claimants of a. Jobseeker's Allowance, b. Incapacity Benefit or Severe Disablement Allowance, c. Employment and Support Allowance, and d. participants in New Deal.

The Health Deprivation and Disability measure combines a measure of premature death with a morbidity/ disability ratio, the emergency admission to hospital and the proportion of adults suffering from mood and anxiety disorders.

The Education measure combines the average points score of pupils taking English, maths and science Key Stage 2/3 and 4 exams (this measure is already part of our controls), the proportion of absences from secondary school, and the proportion of young people aged under 21 not entering higher education.

The Barriers to Housing and Services measure rates the housing conditions for households, i.e., the proportion of all households in an LSOA with insufficient space

\footnotetext{
${ }^{24}$ https://www.nomisweb.co.uk/query/construct/summary.asp? mode $=$ construct\&version $=0 \&$ dataset $=89$
} 
to meet the household's needs, the number of households requiring housing assistance, the proportion of households under 35 whose income is not sufficient to afford its occupation.

The Crime Deprivation measure combines the rates of violence/burglary/theft and criminal damage.

Finally, the Living Environment Deprivation index captures the quality of housing, and two measures relating to air quality and road traffic accidents. 